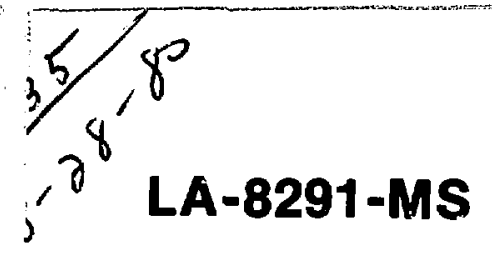

Informai Report
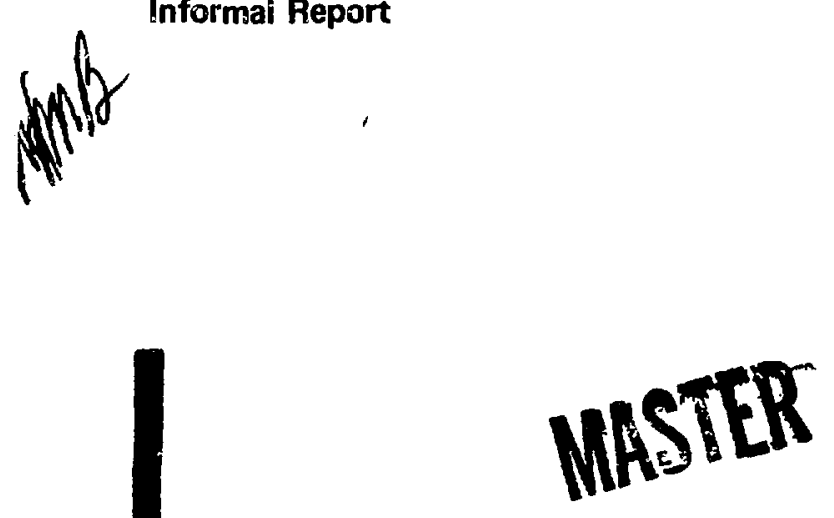

\title{
Lh. 1680
}

Comparative Assessment of

Nuclear Fuel Cycles

Light-Water Reactor Once-Through, Classical Fast Breeder Reactor, and Symbiotic Fast Breeder Reactor Cycles 
LA-8291-MS

Informal Report

UC-80

Issued: June $\mathbf{1 9 8 0}$

\title{
Comparative Assessment of
}

\section{Nuclear Fuel Cycles}

\section{Light-Water Reactor Once-Through,}

Classical Fasi Breeder Reactor, and

Symbiotic Fast Breeder Reactor Cycles

\author{
R. W. Hardie \\ R. J. Barrett \\ J. G. Freiwald
}

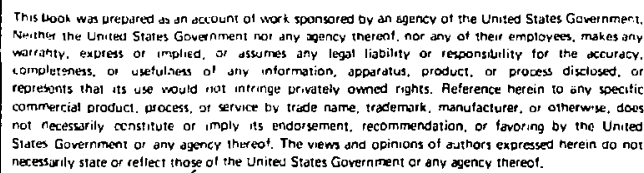


ABSTRACT $\ldots \ldots \ldots \ldots \ldots \ldots \ldots \ldots \ldots \ldots \ldots \ldots \ldots \ldots \ldots \ldots \ldots \ldots \ldots \ldots \ldots \ldots \ldots \ldots$

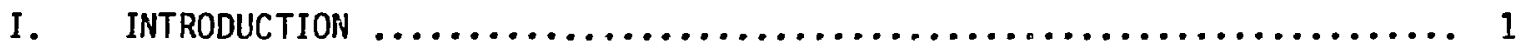

II $\quad$ CONCLUSIONS $\ldots \ldots \ldots \ldots \ldots \ldots \ldots \ldots \ldots \ldots \ldots \ldots \ldots \ldots \ldots \ldots \ldots \ldots$

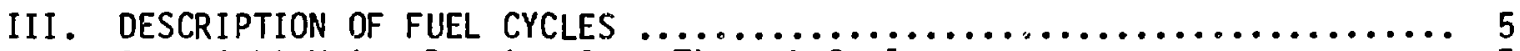

A. Light-Water Reactor Once-Through Cycle ................. 5

B. Classical Fast Breeder Reactor Cycle ................... 6

C. Symbiotic Fast Breeder Reactor Cycle $\ldots \ldots \ldots \ldots \ldots \ldots \ldots \ldots \ldots \ldots \ldots . \ldots$

IV. $\quad$ SYSTEMS INTEGRATOR $\ldots \ldots \ldots \ldots \ldots \ldots \ldots \ldots \ldots \ldots \ldots \ldots \ldots \ldots \ldots \ldots \ldots \ldots$

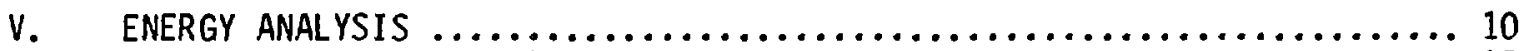

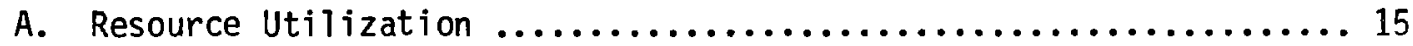

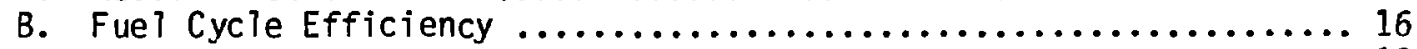

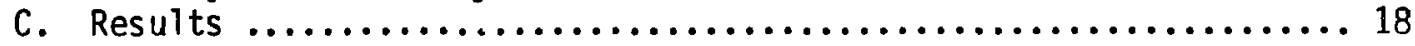

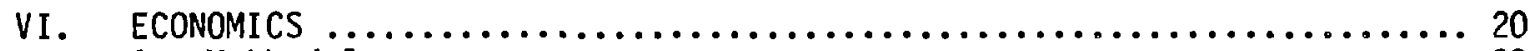

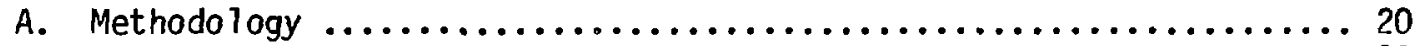

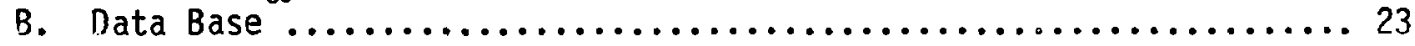

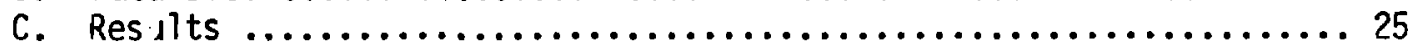

vII. TECHNOIOGICAL EVALUATION $\ldots \ldots \ldots \ldots \ldots \ldots \ldots \ldots \ldots \ldots \ldots \ldots \ldots \ldots \ldots$

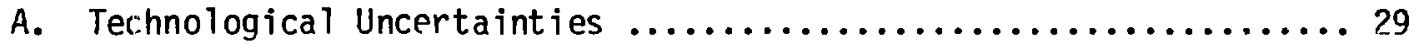

B. Parformance Parameters ..................................

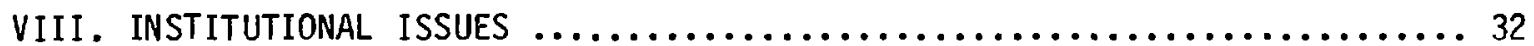

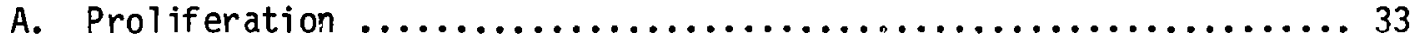

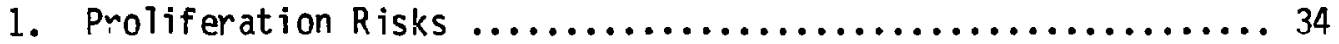

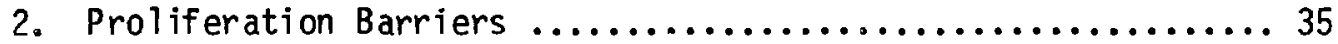

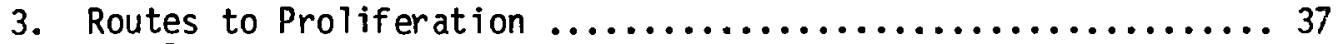

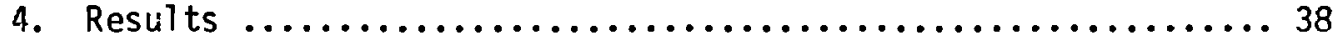

B. Hea]th, Safety, and the Environment $\ldots \ldots \ldots \ldots \ldots \ldots \ldots \ldots \ldots \ldots$

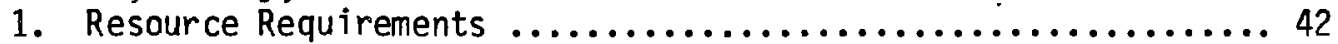

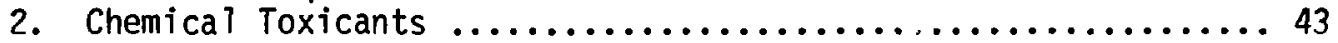

3. Radiological Hazards ........................... 43

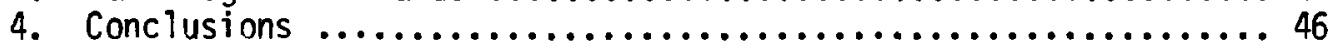

C. Commercialization ............................. 46

1. Research, Development, and Demonstration $\ldots \ldots \ldots \ldots \ldots \ldots \ldots . \ldots 46$

2. Industrial Participation ......................... 47

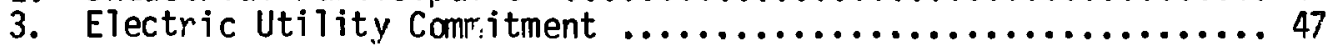

4. Nuclear Facility Licensing .............................. 48

5. Public Acceptance ............................. 48

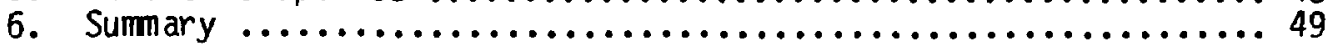

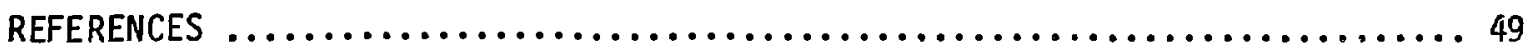

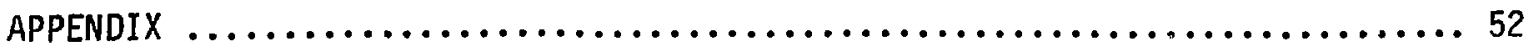


COMPARATIVE ASSESSMENT OF NUCLEAR FUEL CYCLES

Light-Water Reactor Once-Through, Classical Fast Breeder Reactor, and Symbiotic Fast Breeder Reactor Cycles

by

R. W. Hardie, R. J. Barrett, and J. G. Freiwald

\section{ABSTRACT}

The object of the Alternative Nuclear Fuel Cycle Study is to perform comparative assessments of nuclear power systems. There are two important features of this study. First, this evaluation attempts to encompass the complete, integrated fuel cycle from mining of uranium ore to disposal of waste rather than isolated components. Second, it compares several aspects of each cycle-energy use, economics, technological status, proliferation, public safety, and commercial potential--instead of concentrating on one or two assessment areas.

This report presents assessment results for three fuel cycles. These are the light-water reactor once-through cycle, the fast breeder reactor on the classical plutonium cycle, and the fast breeder reactor on a symbiotic cycle using plutonium and $233 \mathrm{U}$ as fissile fuels. The report also contains a description of the methodology used in this assessment. Subsequent reports will present results for additional fuel cycles.

\section{INTRODUCTION}

In the mid-1960's the United States decided to pursue development of the fast breeder reactor (FBR) on the plutonium + uranium fuel cycle as the longterm U.S. nuclear energy strategy. However, in the past few years there has been increasing interest in alternative nuclear fuel cycles. The initial impetus for this interest was the concern that civilian nuclear power progranis could be used, either covertly or overtly, to assist in the acquisition of a nuclear weapons capability.

Other factors have arisen during the past few years which have also combined to stimulate a rethinking of the FBR nuclear strategy. First and 
foremost, recent projections indicate a smaller demand for nuclear power than was earlier estimated. Because the primary advantage of the FBR is to uncouple nuclear power from uranium resources, a reduced nuclear demand means ihat the incentive for the FBR is also reduced. Furthermore, estimates of uranium ore resources have been increasing, and the relative ratio of the capital cost of the FBR to the cost of the light-water reactor (LWR) has been increasing. The aggregate effect of the above three factors is to considerably postpone the point in time when the FBR is needed. Therefore, there is adequate time to re-evaluate the decision made nearly 15 years ago to pursue development of the FBR.

The future of nuclear power in this country is very uncertain at this time. For example, there is considerable doubt among the American people and their elected officials about the safety of nuclear reactors--particularly after the Three-Mile-Island incident. Nevertheless, for this study, we assume that nuclear energy will continue to be an important part of this country's energy us age.

The object of this study is to perform an assessment of the relative merits of various nuclear cycles. This report presents results for three fuelcycle systems--the LWR once-through cycle (LWR-OT), the classical FBR cycle (that is, the plutonium $+{ }^{238} \mathrm{U}$ cycle), and the symbiotic FBR cycle (that is, the plutonium $+{ }^{238} U$ in symbios is with the ${ }^{233} U$ + thorium cycle).

The main purpose for evaluating the LWR once-through cycle is that it is the fuel cycle currently in use in the United States and is a good benchmark with which to compare other fuel cycles. The classical FBR fuel cycle has had top priority within the U.S. for well over a decade. The symbiotic FBR fuel cycls is representative of thorium fuel cycles that have been proposed as a nonproliferation alternative to the classical FBR cycle for reasons that are discussed in this report. Evaluations of additional fuel cycles will be presented in separate reports.

Ar. important feature of this study is that the analysis attempts to evaluate the complete, integrated fuel cycle--from mining and milling of uranium ore to waste disposal. This is important because advantages of isolated components of the fuel cycle frequently are cancelled by disadvantages of other components. For example, plutcrium recycle in LWRS reduces uranium requirements compared to the LWR once-through cycle. Therefore, all problems associated with mining, milling, and enriching uranium are reduced accordingly. 
However, recovering the plutonium from the spent fuel requires chemical reprocessing, which produces problems not encountered with the once-through cycle.

The primary assessment areas that this study uses to evaluate these fuel cycles are net energy potential, economics, technological status, proliferation, public safety, and commercialization potential. Each of these areas is covered in a separate section of this report. In addition to presenting results, this report also discusses the methodology used for each of the above assessment areas. Consequently, subsequent reports describing additional fuelcycle systems will refer to this report for a description of the methodology.

\section{CONCLUSIONS}

Because many assessment areas have to be considered when comparing fue 1 cycles, the final judgement must reflect in some way the full spectrum of issues facing nuclear technologies. The following discussion describes the results from each assessment area and attempts to draw them together into a coherent picture.

The most fundamental measure of an electrical energy system is the amount of energy it can produce. The world's reserves of nuclear fuel are not known with great accuracy, but we know that they will be depleted rapidly if we do not use them effectively and efficiently. The fuel cycles considered in this study fall into two categories: near-term and long-term.

The LWR-OT cycle uses only a small fraction $(\approx 1 / 2$ of $1 \%)$ of the energy available in the world's uranium reserves. Continued reliance on that cycle would deplete the economically recoverable reserves of uranium early in the next century. It should therefore be regarded as a near-term nuclear option.

With the classical FBR cycle, fuel utilization can be improved by a factor of about 125 . The symbiotic cycle can achieve an additional factor of 1.8 by burning thorium as well as uranium. Consequently, both cycles represent long-term, nearly inexhaustible sources of nuclear power. The factor of 1.8 difference between them is not important in our planning horizon.

At some point in the future, conditions will be favorable for a transition from near-term to long-term nuclear options. The timing of that change will depend on the uranium supply, the demand for nuclear power, and a number of economic factors. In choosing among long-term options, society will consider several criteria including relative economic advantages of each option. 
The figure of merit from the economics calculations used to compare competing fuel cycles is the total levelized cost of power delivered to the bus bar. The total power cost in 1978 dollars for the LWR-OT cycle was calculated to be $19.8,24.3$, and $28.9 \mathrm{mills} / \mathrm{kWh}$ for $U_{3} 0_{8}$ prices of $\$ 40, \$ 100$, and $\$ 160 / 16$. For the classical FBR system, the total power cost was calculated to be $25.5 \mathrm{mills} / \mathrm{kWh}$, and for the symbiotic FBR system the total power cost was calculated to be $24.9 \mathrm{mills} / \mathrm{kWh}$. Both of the FBR systems are more expensive than the LWR-0T system until the price of $\mathrm{U}_{3} \mathrm{O}_{8}$ rises above $\$ 100 / 1 \mathrm{~b}$. However, this study indicates that there is very little difference in total power cost between the classical FBR cycle and the symbiotic FBR cycle. Without a clear economic motivation for choosing between these two systems, we must look to other considerations to distinguish between them.

One such factor is technological uncertainty. Based on the progress of ongoing development work, there is little doubt that the classical FBR system could reach an acceptable level of technological readiness when the need for a long-terin nuclear option arises. This is clearly much more in doubt with the symbiotic cycle. Achievement of the symbiotic FBR cycle on the same time scale would require a major new commitment of research and development (R\&D) funds to develop methods for fuel fabrication and reprocessing. To justify such an investment the symbiotic cycle would have to possess some significant advantage over the classical FBR cycle. Without this R\&D commitment, the symbiotic system will not be a viable option.

Another important consideration will be the potential for proliferation of nuclear weapons. Transition to either of these long-term cycles will represent a significant increase in proliferation potential because both longterm options require spent fuel reprocessing and plutonium fuels. The symbiotic cycle has a number of additional problems associated with the use of $233 \mathrm{U}$ fuels. Although these additional problems do not constitute an overwhelming argument against the symbiotic cycle, in our opinion they are serious enough to tip the balance toward the classical FBR system.

The transition to a long-term nuclear system would probably have a small positive impact on the public health and safety aspects of nuclear energy. This would result largely from a reduction in mining and milling operations. We have found no evidence to suggest that either long-term fuel cycle has a significant advantage over the other with respect to the health and safety of the public. 
A final consideration is the difficulty involved in commercializing a new nuclear technology. This complex decision process involves R\&D funding agencies, industrial firms, investors, electric utility companies, government regulators, and the public. The more complicated this web of decisions becomes, the less likely it is that a technology will penetrate the market. Our analysis concludes that the classical FBR cycle has a clear advantage over the symbiotic cycle in this respect.

To summarize, although the two long-term cycles may have similar characteristics, they differ in technological readiness, proliferation potential, and ease of commercialization. The fact that the classical FBR cycle has the advantage in all three areas can be attributed mainly to its relative simplicity as compared to the symbiotic option. Therefore, we conclude that the classical FBR cycle is preferable to the symbiotic FBR system as a long-term nuclear option.

\section{DESCRIPTION OF FUEL CYCLES}

A. Light-Water Reactor Once-Through Cycle

Any comparative assessment of alternative nuclear fuel cycles must include an evaluation of the current U.S. fuel cycle--that is, the light-water reactor once-through (LWR-OT) cycle. The principal components of the LWR-0T cycle (Fig. 1) are uranium mining and milling, conversion of $U_{3} \mathrm{O}_{8}$ to $U_{6}, U F_{6}$ enrichment, fuel fabrication, the nuclear reactor, and discharged fuel storage facilities.

The appendix contains the data base used for all the fuel cycles. With some exceptions, this analys is used the technical characterization data generated for the Nonproliferation Alternative Systems Assessment Program ${ }^{1}$ (NASAP) study. For the LWR-OT cycle, the key fuel cycie component is the light-water reactor design. This analysis used a Combustion Engineering pressurized water design with a power level of $3800 \mathrm{MWt}$, or $1270 \mathrm{MWe}$. The equilibrium fuel enrichment was $3.0 \%{ }^{235} U$ in uranium and the average discharge exposure was $30.4 \mathrm{MWd} / \mathrm{kg}$.

The major shortcoming of the LWR-OT fuel cycle is the poor utilization of the uranium resource. This is discussed in Sec. V.

B. Classical Fast Breeder Reactor Cycle

From the mid-1960's to April 1977, the United States' 1ong-term nuclear energy strategy was the fast breeder reactor (FBR) on the uranium-plutonium 


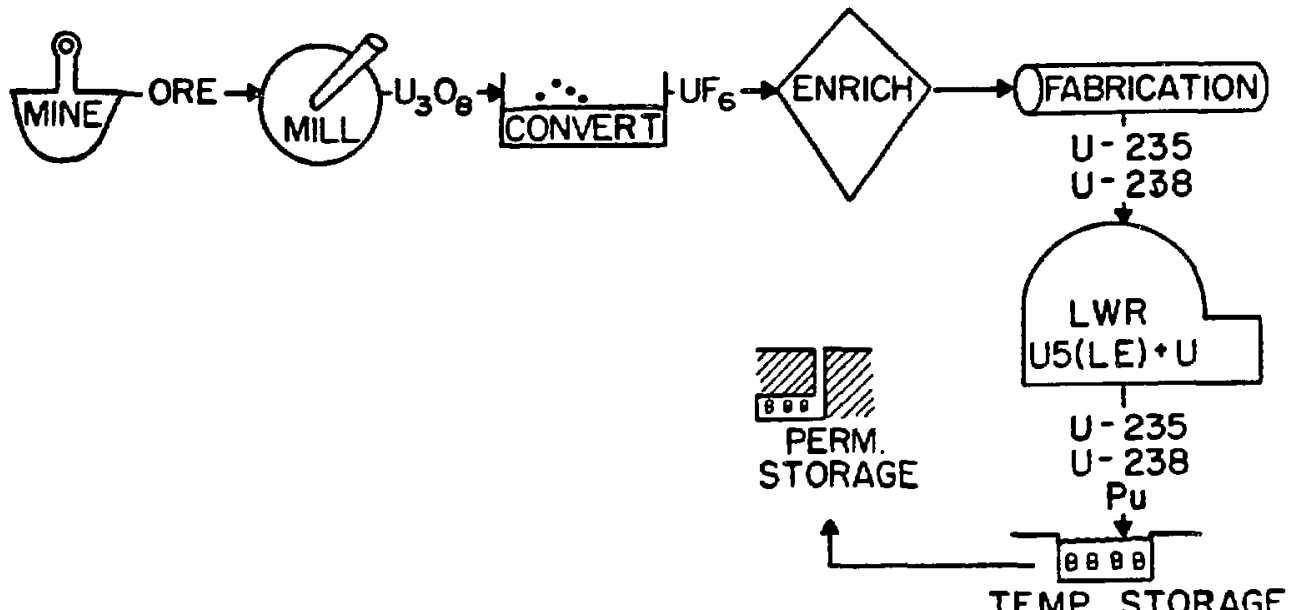

Fig. 1. Low-enriched LWR system on the once-through cycle.

cycle. In this strategy, the spent LWR fuel would be reprocessed and the recovered plutonium loaded into FBRs. These FBRs would use ${ }^{238} U$ as fertile material, breeding plutonium in both the core and the blanket regions.

Because the FBRs produce more plutonium than they consume, there would be an excess of plutonium that could be used as fuel in converter reactors such as LWRs. Eventually, as the uranium resources become increasingly scarce, the uranium-fueled LWRs would phase out and the ecuilibrium fuel cycle would be similar to that illustrated in Fig. 2.

The $f$ ast breeder reactor used in this analysis is based on a typical 1200 MWe (3736 MWt) advanced oxide design. ${ }^{2}$ The breeding ratio for this design was 1.355 , the conversion ratio was 1.040 , and the average core discharge exposure was $62 \mathrm{MWd} / \mathrm{kg}$. The plutonium-fueled light-water reactor used in this analysis was a Combustion Engineering pressurized water design with a power leve 1 of $1270 \mathrm{MWe}$ and an average discharge exposure of $30 \mathrm{MWd} / \mathrm{kg}$.

In contrast to the LWR-OT cycle, the classical FBR cycle is essentially independent of uranium resources. Instead of using the $0.7 \%$ of the uranium that is ${ }^{235} U$, the classical FBR cycle breeds plutonium from ${ }^{238} U$, which is 99.3\% of the uranium. The degree to which this extends the uranium resources is discussed in Sec. V, Energy Analysis.

c. Symbiotic Fast Breeder Reactor Cycile

The first public indication that the classical fast breeder reactor fue 1 cycle had high-level political problems wãs in 0ctober 1976, when President 


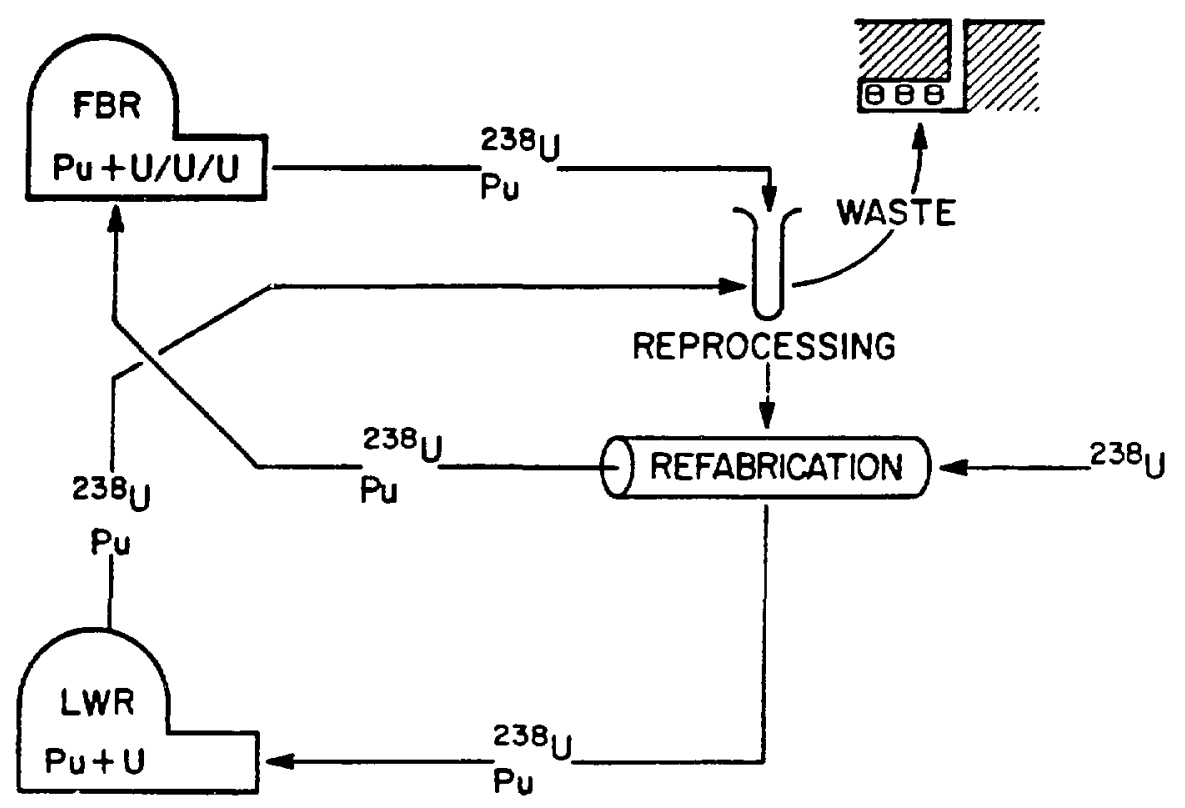

Fig. 2. Classical FBR plutonium fuel system.

Ford $\mathrm{placed}$ a moratorium on reprocessing and stated that a choice may have to be made between nonproliferation and plutonium. If such a choice had to be made, he made it clear that nonproliferation would be the winner. This directly affected the classical FBR because plutonium is its source of fissile fuel.

The second blow to the classical FBR fuel cycle was in April 1977, when President Carter extended President Ford's moratorium on reprocessing. Furthermore, he restructured the U.S. breeder reactor program to emphasize alternative fuel cycle technologies rather than early commercialization.

The concept of the symbiotic FBR cycle shown in Fig. 3 was proposed as a more proliferation-resistant alternative to the classical FBR cycle. ${ }^{3}$ In the symbiotic FBR cycle, the FBR uses thorium as fertile material, either in addition to ${ }^{238} \mathrm{U}$ or in $\mathrm{place}$ of it. For neutronics reasons, most symbiotic FBR cycles restrict the thorium to the blanket regions and leave ${ }^{238} U$ in the core region.

Neutron captures in thorium produce ${ }^{233} U$, which is mixed (denatured) with ${ }^{238} U$ and loaded into an LWR. The advantage of this type of fresh fue 1 is that isotopic enrichment technology is required to produce material suitable for a nuclear explosive. Therefore, denatured ${ }^{233} U$ fresh fuel is comparable to current LWR fresh fuel from a nonproliferation viewpoint. According to Feiveson and Taylor, ${ }^{3}$ the reactors that load denatured fuel could be located 


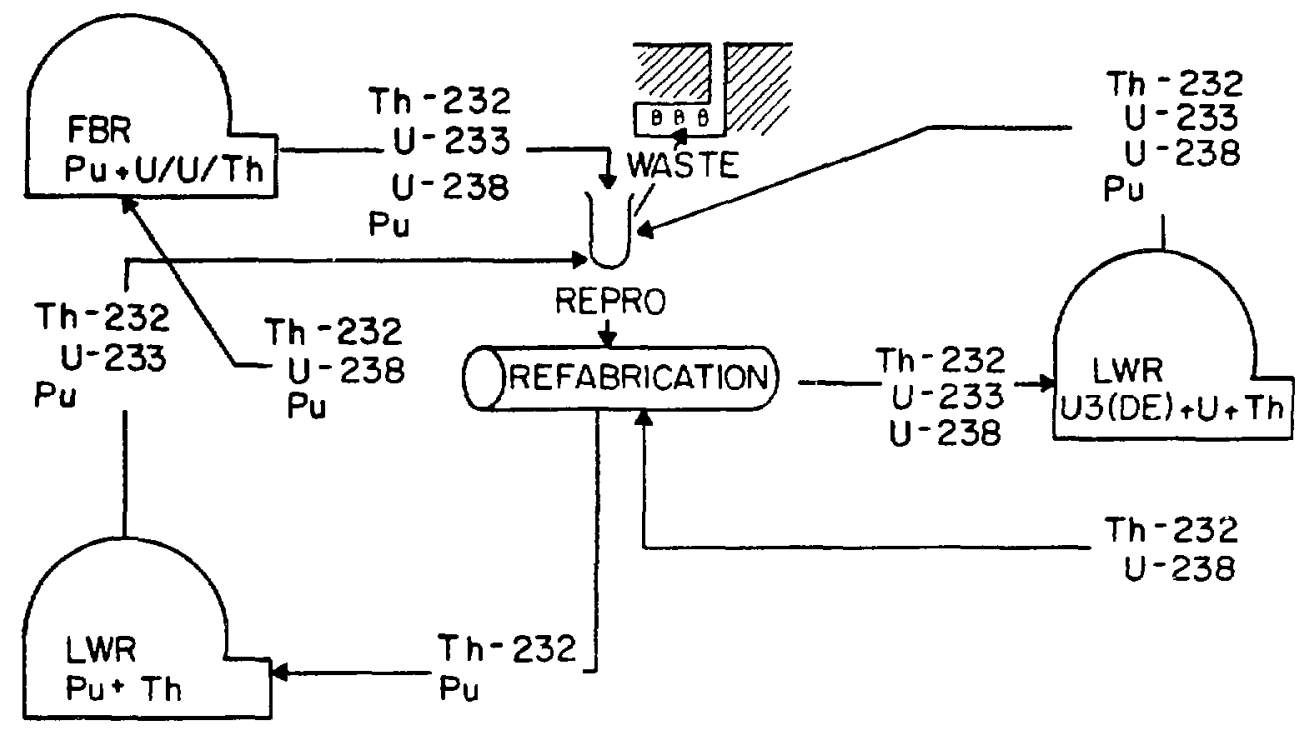

Fig. 3. FBR system with thorium radial blanket.

at national facilities whereas reactors that load plutonium would be restricted to international facilities. Nonproliferation implications of the symbiotic system are discussed in Sec. VIII-A, Proliferation.

The FBR design used for the symbiotic system was similar to the classical FBR design described earlier, except the radial blanket contained thorium instead of $238 \mathrm{U}$. This had minimal impact on the performance parameters; for example, the breeding ratio decreased from 1.355 to 1.349 . The isotopically denatured ${ }^{233} \mathrm{U}$-fueled reactor used in this analysis was a Combustion Engineering pressurized water design fueled with ${ }^{233} \mathrm{U},{ }^{238} \mathrm{U}$, and thorium. The feed $233 \mathrm{U}$ enrichment was $12 \%$ in $233 \mathrm{U}$ plus $238 \mathrm{U}$. The power level was 1270 MWe ( $3800 \mathrm{MWt}$ ), and the average discharge exposure was $34 \mathrm{MWd} / \mathrm{kg}$.

Because the symbiotic FBR produces a small net surplus of plutonium and the denatured LWR also produces a small amount of plutonium, there is excess plutonium available that could be used in a converter reactor.

IV. SYSTEMS INTEGRATOR

An important feature of this analysis is that the assessment is an evaluation of the total integrated fuel cycle instead of the individual components. In order to characterize the interrelationships of the various fuel cycle components into a total system, a Systems Integration Model crmputer code was 
written. The role of the Systems Integration Model (SIM) is shown in Fig. 4. Basically, SIM calculates the equilibrium fractional electrical contribution for each electrical generating plant and determines production requirements for the supporting facilities such as $\mathrm{U}_{3} \mathrm{O}_{8}$ mining and miliing, enrichment, fabrication, and reprocessing. The model's basic assumption is that, except for ${ }^{235} U$, there is no flow of fissile material into or out of the total system. Therefore, the total production of fissile plutonium and ${ }^{233} U$ must be exactly balanced by the consumption and losses of these materiais.

To calculate the above, SIM requires fuel management data (that is, timedependent isotopic charge and discharge data) for each electrical generating plant. Detailed charge and discharge data for each plant type are given in the appendix. A summary of these data is provided in Tables I and II, where the fuel management data were averaged over the lifetime of the plant to simulate equilibrium. Other data requirements for SIM include UF $_{6}$ conversion losses, enriciment losses, fabrication losses, reprocessing losses, the enrichment tails composition, and total system net electrical generating capacit.

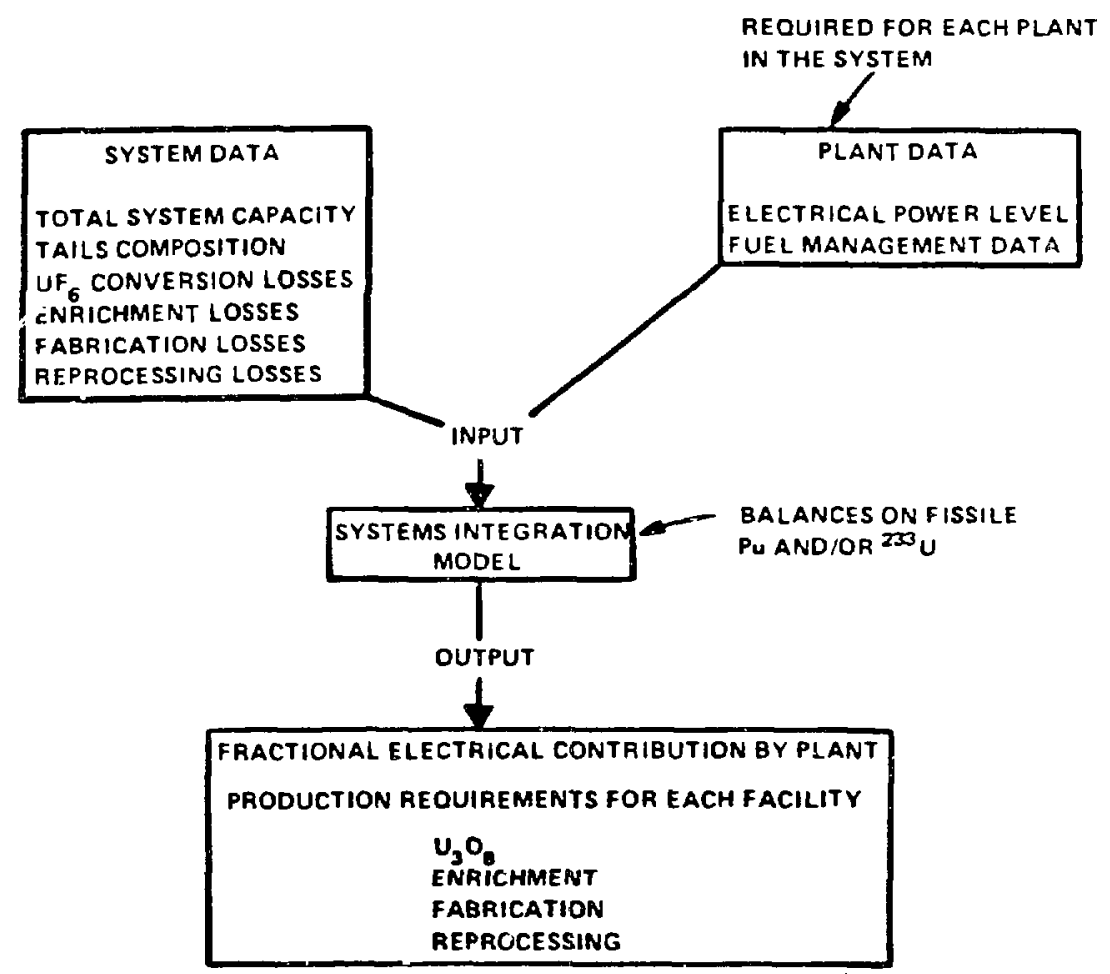

Fig. 4. Systems Integration Model. 
REACTOR CHARACTERISTICSa

\begin{tabular}{|c|c|c|c|c|c|}
\hline \multirow[b]{2}{*}{ Reactor } & \multirow[b]{2}{*}{$\begin{array}{l}\text { Power } \\
\text { Leve } 1 \\
\text { (MWe) } \\
\end{array}$} & \multicolumn{2}{|c|}{ Lifet ime Requirements } & \multicolumn{2}{|c|}{ Equilibrium Conditions } \\
\hline & & $\begin{array}{c}\mathrm{U}_{3} \mathrm{O}_{8} \\
\left.\text { (tons } \mathrm{U}_{3} \mathrm{O}_{3} / \mathrm{GWe}\right) \\
{[\text { Charge }} \\
\text { Discharge } \\
\text { Net }(c-d)] \\
\end{array}$ & $\begin{array}{c}\text { Eur ichment } \\
(106 \mathrm{~kg} \text { SWU/GWe) } \\
{[\text { Charge }} \\
\text { Discharge } \\
\text { Net }(c-d)] \\
\end{array}$ & $\begin{array}{c}\text { Fabrication } \\
\text { Requirements } \\
{[\text { MTHM/(GWe•yr)] }}\end{array}$ & $\begin{array}{l}\text { Core } \\
\text { Discharge } \\
\text { Exposure } \\
\text { (MWd/kg HM) } \\
\end{array}$ \\
\hline LWR $-U 5$ (LE) +U & 1270 & $\begin{array}{l}5675 \\
1403 \\
4272\end{array}$ & $\begin{array}{l}3.40 \\
0.20 \\
3.20\end{array}$ & 27.1 & 30 \\
\hline$\cdots \cdots$ & -- & $\cdots 0^{-\cdots}$ & $\cdots$ & $\cdots \cdots$ & $\cdots$ \\
\hline FBR-Pu+U/U/U & 1196 & $\begin{array}{l}0 \\
0\end{array}$ & $\begin{array}{l}0 \\
0\end{array}$ & $13.0 / 7.3 / 5.9^{b}$ & 62 \\
\hline LWR-Pu+U & 1270 & $\begin{array}{r}987 \\
0 \\
987\end{array}$ & $\begin{array}{l}0 \\
0 \\
0\end{array}$ & 27.0 & 30 \\
\hline$\cdots-\cdots$ & - & $\begin{array}{c}-\cdots \\
0\end{array}$ & $\cdots$ & $-\cdots-\cdots$ & $\cdots$ \\
\hline$F B R-P u+U / U / T h$ & 1196 & $\begin{array}{l}0 \\
0\end{array}$ & $\begin{array}{l}0 \\
0\end{array}$ & $13.0 / 7.3 / 5.3^{b}$ & 62 \\
\hline$L W R-U 3(D E)+U+T h$ & 1270 & $\begin{array}{l}0 \\
0 \\
0\end{array}$ & $\begin{array}{l}0 \\
0 \\
0\end{array}$ & 24.6 & 34 \\
\hline LWR-Pu+Th & 1270 & $\begin{array}{l}0 \\
0 \\
0\end{array}$ & $\begin{array}{l}0 \\
0 \\
0\end{array}$ & 24.6 & 34 \\
\hline
\end{tabular}

avalues do not include losses such as fabrication and reprocessing losses. Capacity factor is $70 \%$. bCore/Axial Blanket/Radial Blanket. 
TABLE II

AVERAGE FISSILE MASS FLOWS

\section{$[\mathrm{kg} /($ Gle $\bullet y r)]$}

\begin{tabular}{|c|c|c|c|c|}
\hline Reactor & $\begin{array}{l}233 \mathrm{U} \\
\text { [Charge } \\
\text { Discharge } \\
\text { Net (c-d)] } \\
\end{array}$ & $\begin{array}{l}235 u \\
\text { [ Charge } \\
\text { Discharge } \\
\text { Net (c-d)] }\end{array}$ & $\begin{array}{l}\text { Fissile Pu } \\
\text { [Charge } \\
\text { Discharge } \\
\text { Net (c-d)] } \\
\end{array}$ & $\begin{array}{c}\text { Total Fissile } \\
\text { [Charge } \\
\text { Discharge } \\
\text { Net }(c-d)] \\
\end{array}$ \\
\hline$L W R-L 5(L E)+U$ & $\begin{array}{l}0 \\
0 \\
0\end{array}$ & $\begin{array}{l}798 \\
236 \\
562\end{array}$ & $\begin{array}{c}0 \\
176 \\
-176\end{array}$ & $\begin{array}{l}798 \\
412 \\
386\end{array}$ \\
\hline FBR-PU+U/U/U & $\begin{array}{l}-- \\
0 \\
0 \\
0\end{array}$ & $\begin{array}{r}-\overline{73} \\
51 \\
22\end{array}$ & $\begin{array}{l}-1312 \\
1634 \\
-322\end{array}$ & $\begin{array}{c}-1385 \\
1685 \\
-300\end{array}$ \\
\hline LWR-PU+U & $\begin{array}{l}0 \\
0 \\
0\end{array}$ & $\begin{array}{r}180 \\
112 \\
68\end{array}$ & $\begin{array}{r}1080 \\
851 \\
229\end{array}$ & $\begin{array}{r}1260 \\
963 \\
297\end{array}$ \\
\hline FBR-Pu+U/U/Th & $\begin{array}{r}-- \\
0 \\
132 \\
-132\end{array}$ & $\begin{array}{r}---- \\
55 \\
35 \\
20\end{array}$ & $\begin{array}{l}-1314 \\
1497 \\
-183\end{array}$ & $\begin{array}{c}--1369 \\
1664 \\
-295\end{array}$ \\
\hline$L W R-U 3(D E)+U+T h$ & $\begin{array}{l}758 \\
466 \\
292\end{array}$ & $\begin{array}{l}37 \\
45 \\
-8\end{array}$ & $\begin{array}{r}0 \\
64 \\
-64\end{array}$ & $\begin{array}{l}795 \\
575 \\
220\end{array}$ \\
\hline LWR-Pu+Th & $\begin{array}{r}0 \\
266 \\
-266\end{array}$ & $\begin{array}{r}0 \\
3 \\
-3\end{array}$ & $\begin{array}{r}1437 \\
829 \\
608\end{array}$ & $\begin{array}{r}1437 \\
1098 \\
339\end{array}$ \\
\hline
\end{tabular}

aValues do not include losses such as fabrication and reprocessing losses. Capacity factor is $70 \%$. 
SIM results for the light-water reactor once-through cycle are shown in Fig. 5. All fuel cycle systems were normalized to a one GWe net electrical capacity operating at a $70 \%$ capacity factor. For once-tinrough fuel cycles, the role of the systems integrator is relatively simple. Probably the most important SIM results for such systems are the uranium and enrichment raquirements. The LWR-OT system requires 192 short tons of $\mathrm{U}_{3} \mathrm{O}_{8}$ per year and 115 $x 10^{3}$ separative work units of enrichment per year.

SIM results for the classical FBR cycle are shown in Fig. 6. For this fuel cycle, the relative number of each type of reactor is determined by the production and consumption rates of fissile plutonium. For the reactor designs used in this ana!ysis, $46 \%$ of the total electricity is produced from the FBR and $54 \%$ is produced from the plutonium-fueled LWR.

Finally, SIM results for the symbiotic FBR cycle are shown in Fig. 7. This illustrates the most complicated type of fuel-cycle system analyzed by the Systems Integration Mode1. For symbiotic systems, the relative number of each type of reactor is deterinined by the production and consumption rates of both fissile plutonium and ${ }^{23} \mathrm{U}$. Almost half of the total electricity is produced from the FBR and $16 \%$ is produced from the plutonium-plus-thoriumfueled LWR. The denatured ${ }^{23}$ U-fueled LWR contributes $35 \%$ to the total electrical generating capacity. Therefore, using the criterion of Feiveson and Taylor that reactors loading plutonium are limited to international facilities, $35 \%$ of the total generating capacity could be located in national facilities.

\section{v. ENERGY ANALYSIS}

The most fundamental measure of an electrical supply system is the total amount of energy it is capable of delivering to the distribution grid. There is little incentive to develop a technology that exploits a limited energy resource, uses only a small fraction of a resource, or consumes nearly as much energy as it produces.

All nuclear fuel cycles are designed to exploit our reserves of uranium. Some cycles also derive energy from thorium. Although there is uncertainty about the size of these resources, they are certainly larger than the combined world reserves of gas, oil, and coal. 4

However suclear fuel cycles vary widely in their potential ability to extract this energy and deliver it to electrical consumers. Two factors 


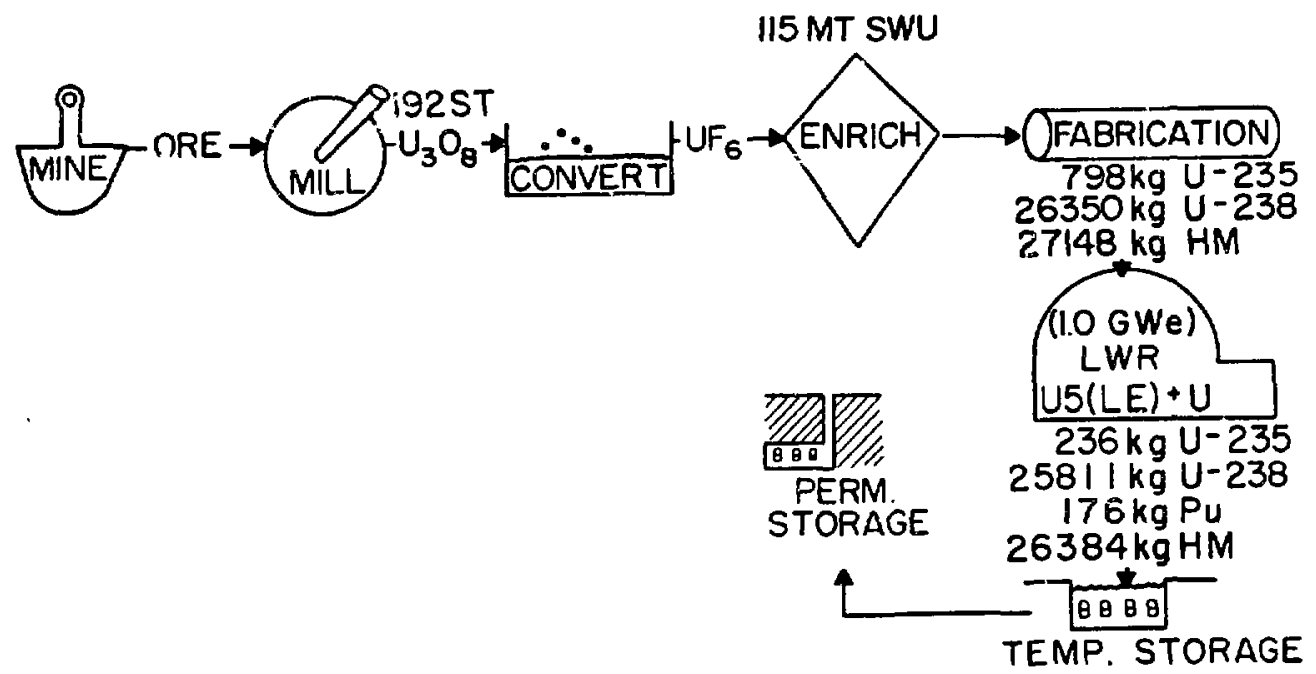

Fig. 5. Low-enriched LWR system on the once-through cycle (1 GWe system, $70 \%$ capacity).

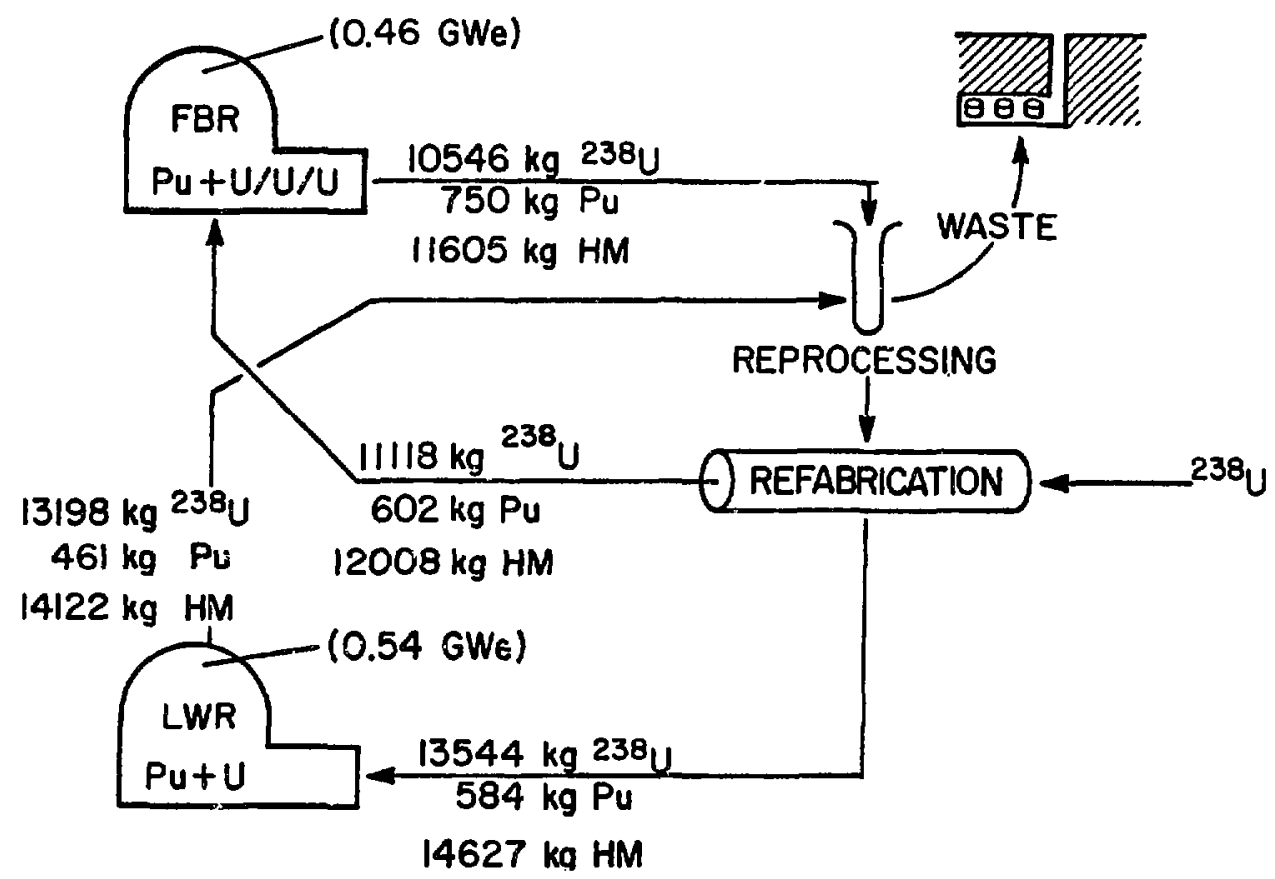

Fig. 6. Classical FBR plutonium fuel system (1 GWe system, $70 \%$ capacity). 


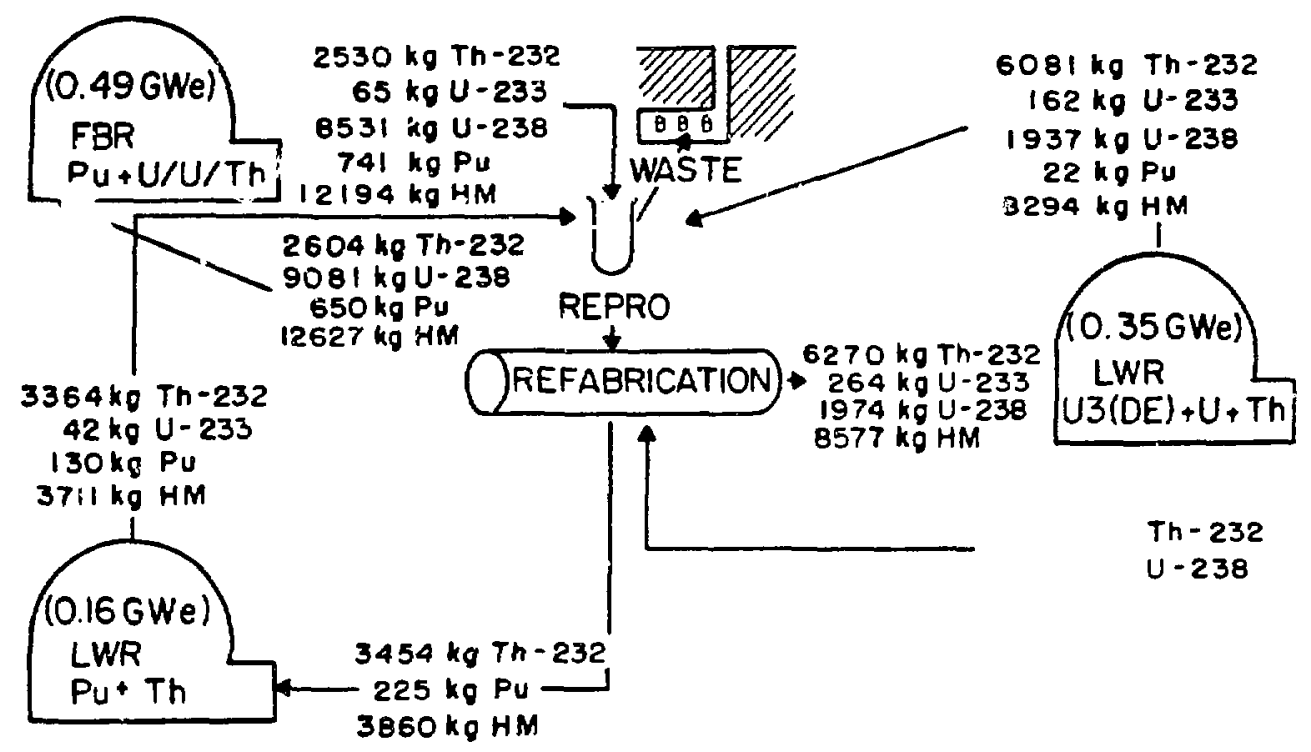

Fig. 7. FBR system with thorium radial blanket (1 GWe system, $70 \%$ capacity).

contribute to these differences. Some fue 1 cycles discard or lose a larger fraction of the fissionable material than others. This phenomenon is discussed below in Resource Utilization. In addition, fuel cycles consume varying amounts of energy for their own operation. This effect is described below in Fuel Cycle Efficiency.

As a figure of merit in comparing fuel cycles, we have defined the parameter, which we call Net Energy Potential. This dimensionless parameter is defined as tra net energy that can be produced by the cycle, expressed as a fraction of the uranium resources it exploits. By expressing this parameter as a fraction, we can compare the performance of fuel cycles independently of estimates of the actual extent of uranium resources. Because some fuel cycles also extract energy from thorium, it is possible for to be greater than unity.

\section{A. Resource Utilization}

In any fuel cycle, only a fraction of the uranium can be burned, either directly through fissioning of $235 \mathrm{U}$ or indirectly through fissioning of bred plutonium. The remainder of the material is either deliberately discardedin the form of enrichment tails and spent fuel, or lost in reprocessing and refabrication plants. The uranium utilization fraction $F_{u}$ is calculated using material-bal ance data from the systems integration model, 


$$
F_{U}=\frac{M_{U}{ }^{B}}{M_{U}{ }^{B}+M_{U}{ }^{L}+M_{U}, D} \text {, }
$$

where $M_{U, B}$ is the mass of $235 U$ and plutonium burned, $M_{U, L}$ is the mass of uranium and plutonium lost and $M_{U, D}$ is the mass of uranium and plutonium discarded.

For the LWR-OT cycle there are small amounts of material lost in fabrication, b't most of the uranium is discarded as eririchment tails and spent fuel. Consequently, only a sma.11 fraction of the uranium is burned (Tabie III). This fraction could be improved somewhat by a combination of improvements to the cycle. These improvements would include lowering the enrichment tails assay from $0.2 \%$ to $0.1 \%$, improving LWR burnup by $15 \%$, and recycling the unused ${ }^{235} \mathrm{U}$ and plutonium from spent fuel.

In the classical FBR and symbiotic fuel cycles, no uranium is discarded deliberately. However, the repeated reprocessing and refabrication of the spent fuel results in the loss of a sizeable fraction of the uranium and plutonium. For this reason, the two breeder cycles, although considerably better than the LWR-OT cycle, do not burn all the uranium. The uranium utilization fraction for the symbiotic system is actually somewhat better than the classical FBR cycle (Table III). This is because almost all of the uranium and plutonium in the symbiotic system is used in reactor cores where it can achieve high burnups between reprocessing cycles. In the classical FBR, much of the uranium resides in the radial blanket, where it achieves very low burnups.

In addition to the energy extracted from uranium, several fuel cycles also derive energy from thorium and its capture product ${ }^{233} U$. The symbiotic cycle falls in this category. To account for this fact, we have defined a parameter called the thorium premium factor $\mathrm{P}_{\mathrm{T}}$. it is calculated according to the formula

$$
P_{T}=1+\frac{M_{T H, B}}{M_{U, B}}
$$

where $M_{T H, B}$ is the mass of thorium and ${ }^{233} U$ burned, as calculated by the systems integration model. The symbiotic cycle has a thorium premium factor of 1.62. The other two cycles have a value of unity. 
TABLE II I

URANIUM UTILIZATION FRACTION

\begin{tabular}{ccc} 
LWR-OT & & $\mathrm{F}$ \\
\hline Reference & $:$ & 0.0052 \\
0.1\% Tails & $:$ & 0.0060 \\
Improved LWR & $:$ & 0.0061 \\
Recycle & $:$ & 0.0080 \\
Combination & $:$ & 0.0102 \\
Classical FBR & $:$ & 0.63 \\
Symbiotic FBR & $:$ & 0.70
\end{tabular}

\section{B. Fuel Cycle Efficiency}

A1l electrical production systems consume some of the energy they produce. In the case of nuclear reactors, a fraction of the electricity is recirculated continuously within the plant to run the massive pumps. Additionally, fuel-cycle activities such as mining, milling, fluorination, enrichment, fabrication, and reprocessing require varying amounts of operating energy. Furthermore, energy is required to construct these facilities and manufacture their complex equipment. This is called embodied energy.

Using methods and data from several sources ${ }^{5-11}$, we have constructed a data base (Appendix) which specifies the operating and embodied energy requirements of several types of reactors and fuel-cycle facilities. While compiling the data base, we noted sizeable discrepancies in the results from different data sources and different methods. We were forced to make choices in some cases and to average in others. The requirements for transportation of nuclear materials and for waste management were found to be very small. Consequently they were neglected with no significant loss of accuracy. However, the most significant energy requirements are generally the most accurately known because they happen to be based on operating experience. Varying the data base within reasonable bounds produced no substantive change in the results of the analysis. 
All energy requirements are quoted in terms of their electrical equivalent rather than thermal equivalent. Where the data source quoted the thermal equivalent of energy inputs, a thermal-to-electrical conversion factor of 0.35 was applied. In the subsequent calculations of fuel-cycle efficiency, the inputs were compared with the electrical production of the reactor rather than the thermal output.

For each fuel cycle, the systems integration model (SIM) calculates what fraction of the annual output from each fuel facility is required to support the reactors in the cycle. These factors are multiplied by the annual energy requirements of the facilities (including the reactors). The sum of these products is the annual energy requirement $Q_{C}$ of the fuel cycle. The annual energy output of the reactors $Q_{F}$ is calculated from the reactor capacities and capacity factors. The fuel cycle efficiency is defined as;

$$
\varepsilon_{C}=\frac{Q_{F}-Q_{C}}{Q_{F}} \text {. }
$$

A breakdown of energy requirements for the three fue 1 cycles, each having a 1000 MWe capacity, is given in Table IV. All three fuel cycles have efficiencies well in excess of $90 \%$, a fact that leaves little room, and little incentive, for improvement. The LWR-OT cycle lags somewhat behind the other two cycles because of the conspicuous energy requirements of gaseous diffusion enrichment. Substitution of new enrichment technologies, such as the gas centrifuge or laser isotope separation could bring the LWR-OT cycle efficiency up to the level of the other two.

The energy requirements of the reactors are important sources of fue 1 cycle inefficiency. With the exception of gaseous diffusion enrichment, the operating energy requirements of fuel-cycle facilities are minimal. The breakdown presented in Table $V$ shows that embodied energy is not as important as operating energy. 
TABLE IV

ANNUAL ENERGY REQUIREMENTS AND FUEL CYCLE EFFICIENCIES FOR THREE OPTIONS WITH 1000 MWE CAPACITY

Facility

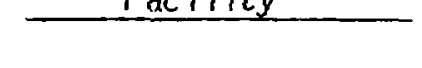

Annual Energy Requirement (GWhe) ${ }^{b}$

LWR-OT

\section{Classical FBR}

Symbiotic FBR
Mining
Milling
Fluorination
Enrichment
$\quad$ (gaseous diffusion)

Fabrication

Reactors

Reprocessing

Total

Fuel Cycle Efficiency
1.2

7.3

2.8

277.6

2.2

164.3

$\frac{-}{455.4}$

0.927
4.2

5.3

172.8

173.3

$\frac{2.7}{179.7}$

$\frac{2.6}{182.1}$

0.971

0.971

$\mathrm{a}_{\mathrm{CF}_{F}}=6133$ GWhe.

b GWhe refers to a million $\left(10^{6}\right)$ kWhe of electrical output.

C. Results

Our overall figure of merit $n$ can be expressed as a product of the uranium utilization factor $F_{U}$, the thorium premium factor $P_{T}$ and the fue $?$ cycle efficiency $\varepsilon_{C}$,

$$
\eta=F_{U} \times P_{T} \times \varepsilon_{C}
$$

Table VI presents the relevant data for all three fuel cycles. Although the efficiencies of all three fuel cycles are excellent, the LWR-OT cycle has an anomalousiy low net energy potential. Continued dependence on this cycle will result in a rapid transition to low-grade, high-priced uranium ore. How rapidly it occurs will depend on the extent of the uranium reserves and the demand for nuclear energy. Both of these factors have proven difficult to est imate in recent years. 


\section{TABLE $V$}

OPERATING AND EMBODIED ENERGY REQUIREMENTS OF NUCLEAR FUEL CYCLES

Annual Energy Requirement (GWhe)

Embodied

Energy

Operating

Energy

Total
Classical FBR

59.4

120.3

$\overline{179.7}$
Symbiotic FBR

61.3

120.8

402.0

$\overline{455.4}$

The salient result of this energy analysis is to distinguish between near-term and long-term nuclear options. The LWR-OT cycle falls into the former category. The other two cycles clearly qualify as long-term sources of electrical energy.

VI. ECONOMICS

A. Methodology

One important criterion for assessing the attractiveness of different methods of generating electricity is the estimation of what the bus bar cost might be. The principal reasons for performing economics calculations are twofold. First, economics calculations are useful to determine under what conditions, if any, a particular fuel cycle might be competitive with other

TABLE VI

SUMMARY OF ENERGY ANALYSIS

LWR-OT

$\mathrm{F}_{\mathrm{U}}$

$\mathrm{PT}_{\mathrm{T}}$

$\varepsilon_{\mathrm{C}}$

$\eta$
0.0052

1.0

0.93

$\overline{0.0048}$
Classical FBR

0.63

1.0

0.97

0.61
Symbiotic FBR

0.70

1.62

0.97

$\overline{1.10}$ 
fuel cycles. This is important because the results of such calculations can identify particular areas that are large cost contributors and therefore indicate areas where efforts in cost reduction should be concentrated.

Second, sensitivity analyses are very important to determine the possible impact that a new technology might have on the total power cost of a particular fuel cycle. An example might be the reduction in total power cost resulting from laser isotopic enrichment compared to gaseous diffusion enrichment. It is necessary to consider the total integrated fuel cycle because the impact of such a technology yould vary, depending on the fuel cycle. For example, the impact of laser isotopic enrichment would be larger for the LWR-OT cycle compared to a cycle where the discharged fue 1 was reprocessed and reloaded into an LWR.

The cost of some items for generating electricity may vary during the lifetime of a power plant (for example, the price of uranium probably will increase as the higher grade resources are depleted). However, the usual method for comparing costs from different methoc's of generating electricity is to calculate levelized (constant) total power costs.

The fundamental assumption in computing levelized total power costs is that the income over the lifetime of a project must equal the expenses of a project. The income is derived from the revenue received from the sale of electricity. The expenses include the recovery of the investment, return on the investment, fuel costs, taxes, and any other expenses associated with the project.

Reference 12 provides a detailed description of a procedure for calculating levelized total power costs for nuclear power plants. This analys is used the computer code LPC (Levelized Power $\underline{C}$ ost), 13 which contains a very simi1 ar procedure. In addition, the LPC code also calculates power costs for coal-, gas-, and oil-fueled power plants.

Figure 8 illustrates the typical components of the levelized total power cost. This particular calculation was for a light-water rear.tor on the oncethrough cycle. The power cost normally is split into three components: capital, operation and maintenance, and fue 1 cycle. The fuel cycle component consists of several subcomponents including $\mathrm{U}_{3} \mathrm{O}_{8}$ purchases, enrichment services, fabrication costs, waste storage and shipment costs, etc. 
The goal of this study is to provide a comparative assessment of fue 1 cycle systems, not individual reactors. Therefore, for fuel cycles that contain more than one reactor type, the total power cost of the complete system must be calculated. A related problem is the determination of the value of the artificially produced fissile fuel (that is, fissile plutonium and $233(U)$. This study uses the concept of indifference prices to determine fissile fuel prices. The logic of indifference value calculations is the following.

Consider a closed fuel-cycle system such as the classical FBR cycle consisting of two reactor types where one reactor is a net producer of plutonium and the other reactor is a net consumer of plutonium. If the value of the plutonium produced in this system is very high, the total power cost of the plutonium-producing reactor would be less than the power cost of the plutonium consumer. Consequently, more plutonium-producing reactors would be built to take advantage of the reduced costs. With the increased availability of the produced fissile plutonium, its value would eventually decrease until an economic balance was achieved between the cost of producing and consuming th. fue 7 . At equilibrium, the indifference value of plutonium would be that price which equalizes the total power cost of the two reactor types. This is shown in Fig. 9. The relative number of reactors of each type built will be determined by the plutonium production and consumption rates of the reactors.

The above logic can be extended to a closed system such as the symbiotic FBR cycle consisting of three reactor types producing and consuming both plutonium and ${ }^{233} \mathrm{U}$. For this type of system, the indifference values of the plutonium and ${ }^{233} U$ are obtained by setting the total power costs of all three reactor types equal. For both fuel-cycle systems, the relative number of each type of reactor is determined by the fissile fuel production and consumption rates as described in Sec. IV.

There are obviously large uncertainties in estimating some of the key cost parameters needed to calculate total power costs, particularly for technologies whose commercialization is far into the future. Consequently, small differences in total power cost are not significant, although opinions vary widely as to what constitutes small differences.

Finally, the treatment of inflation in the calculation of total power costs should be explained. Except for small income tax effects, the impact of wholly anticipated inflation does not change the relative cost rankings of 


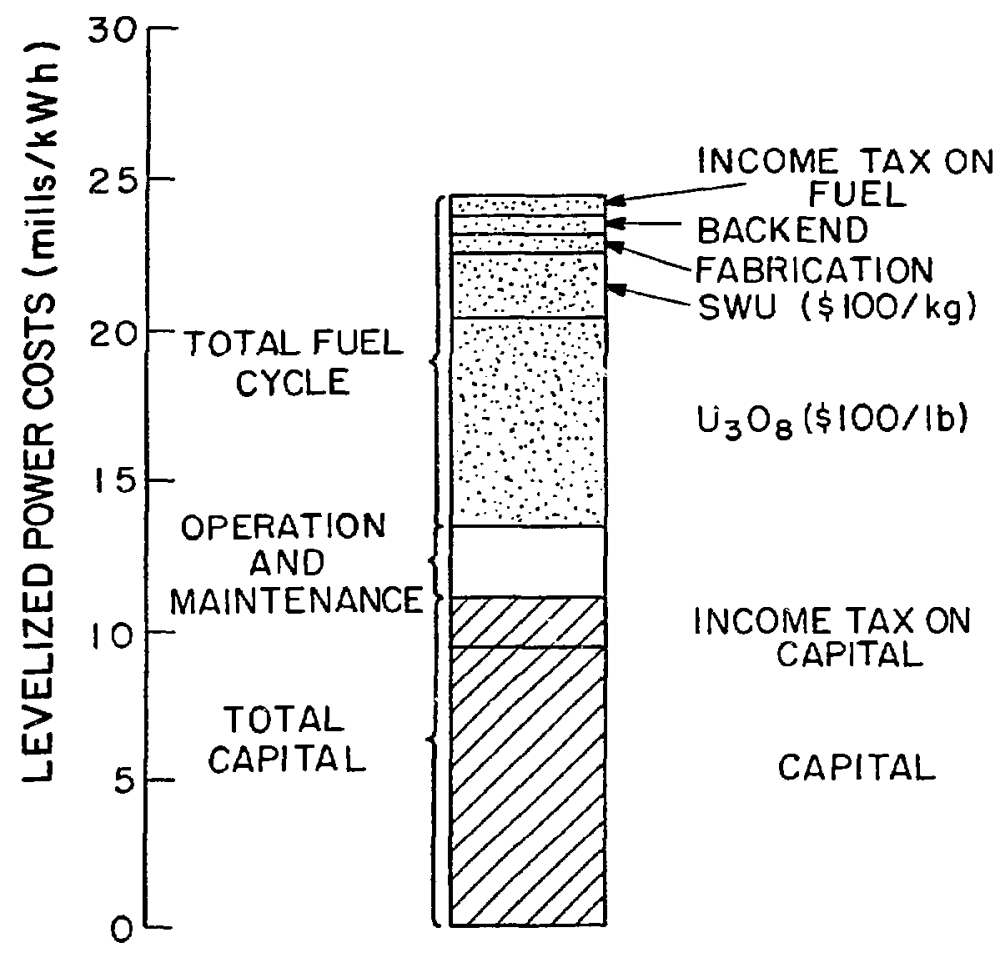

Fig. 8. Levelized power cost components for LWR-U5 $(L E)+U$ on the once-through cycle.

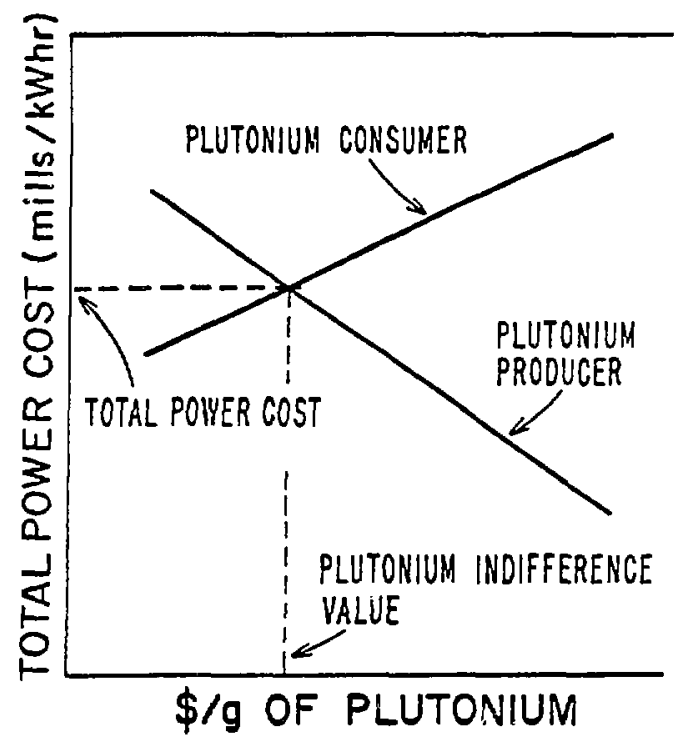

Fig. 9. Determination of plutonium indifference value. 
various technologies. Therefore, this analysis uses constant 1978 dollars for all calculations. This is preferable rause (1) cost datā are easier to generate in real dollars, (2) the results are more meaningful if they can be related to today's costs, and (3) accurately predicting inflation rates is impossible.

\section{B. Data Base}

The economics calculations for the three fuel-cycle systems evaluated in this study require a significant amount of data, as shown in the appendix. However, these data can be reduced to the few key economics parameters shown in Tables VII and VIII. Although these are only a fraction of the parameters actually used in the economics calculations, they are by far the most important. The remaining parameters can be varied over a quite large range with only a small impact on the results of the total power cost calculations.

The key reactor-dependent economic parameters are capital cost, operation and maintenance costs, and fuel-handiing costs. Comparing the reactordependent parameters, the principal difference is that FBR capital costs are $39 \%$ higher than LWR capital costs. Also, handling costs for fuel with plutonium are considerably more expensive than for fuel with ${ }^{235} U$. Furthermore, handling costs for fuel with ${ }^{233} U$ are even more expensive than for fuel with plutonium.

The key system parameters are money costs, enrichment costs, and $U_{3} 0_{8}$ costs. Three different $\mathrm{U}_{3} \mathrm{O}_{8}$ prices were chosen. The $\$ 40 / 1 \mathrm{~b}$ cost is typical of today's prices, whereas the $\$ 100 / 1 \mathrm{~b}$ and $\$ 160 / 1 \mathrm{~b}$ costs are intended to reflect fucure prices. The money costs are from the NASAP study. The basis for these values is given in Ref. 14, where historical electric utility money costs from 1949 to 1973 were used to develop interest rates compatible with a zero rate of inflation.

The other important data required for the economics calculations are the fuel management information, that is, isotopic charge and discharge data for each year the plant operates. Detailed charge and discharge data for each reactor type are given in the appendix. A summary of this data is provided in Tables I and II, where the fue 1 management data were averaged over the lifetime of the plant. It should be emphasized that the economics model didn't actually use the averaged data, but it is useful when trying to understand the results of the calculations. 
TABLE VII

KEY REACTOR-DEPENDENT ECONOMIC PARAMETERS ${ }^{a}$

\begin{tabular}{|c|c|c|c|c|c|}
\hline Reactor & $\begin{array}{c}\text { Capital } \\
\text { Cost } \\
\text { (\$/kWe) }\end{array}$ & $\begin{array}{l}\text { Opera } \\
\text { Mainte } \\
\text { Cost } \\
\text { Fixed } \\
\end{array}$ & $\begin{array}{l}\text { on and } \\
\text { ance } \\
0 \$ \$ / y r) \\
\text { ariable } \\
\end{array}$ & $\begin{array}{l}\text { Total } \\
\text { Front End } \\
\text { Cost } \\
(\$ / \mathrm{kg} \mathrm{HM})^{\mathrm{b}}\end{array}$ & $\begin{array}{l}\text { Total } 1 \\
\text { Back End } \\
\text { Cost } \\
(\$ / \mathrm{kg} \mathrm{HM})^{\mathrm{b}} \\
\end{array}$ \\
\hline $\begin{array}{l}\text { LWR-U5(LE)+U } \\
\text { (once-through) }\end{array}$ & 690 & 16.5 & 1.3 & 110 & 135 \\
\hline$F B R-P(U+U / U / U$ & 960 & 20.3 & 1.2 & $\begin{array}{l}580^{a} \\
130^{b}\end{array}$ & $\begin{array}{l}665^{a} \\
600^{b}\end{array}$ \\
\hline$L W R-P u+U$ & 690 & 16.5 & $1: 3$ & 370 & 445 \\
\hline FBR-Pu+U/U/Th & 960 & 20.3 & 1.2 & $\begin{array}{l}580 c \\
140 d\end{array}$ & $\begin{array}{l}665 \\
665\end{array}$ \\
\hline$L W R-U 3(D E)+U+T h$ & 690 & 16.5 & 1.3 & 570 & 485 \\
\hline LWR-Pu+Th & 690 & 16.5 & 1.3 & 380 & 485 \\
\hline
\end{tabular}

TABLE VIII

KEY SYSTEM ECONOMIC PAR.AMETERSa

Money Costs

Debt interest, $\%$

2.5

Equity return, \%

7.0

Debt fraction

0.55

Equity fraction

0.45

Effective return, \%

4.5

Income Tax rate, \%

50

Reference Enrichment Cost, $\$ / \mathrm{kg}$ SWU

100

Reference $\mathrm{U}_{3} \mathrm{O}_{8}$ Price, $\$ / L B U_{3} \mathrm{O}_{8}$

40,100 , and 160

${ }^{a}$ A11 costs are real costs in 1978 dollars. 
Finally, because coal is nuclear power's closest competition, the total power cost of a coal plant was calculated to put nuclear power costs into perspective. The capital cost of the coal plant was assumed to be $\$ 530 / \mathrm{kWe}$, or about $77 \%$ of the LWR capital cost. The heat content of the coal was assumed to be $10,000 \mathrm{Btu} / 1 \mathrm{~b}$. Levelized total power costs were calculated for $\$ 10 / S T$, $\$ 25 / \mathrm{ST}$, and $\$ 40 / \mathrm{ST}$ of coal. The results of the total power cost calculations are compared with the LWR-OT cycle in Fig. 10.

Figure 11 shows the price of coal and $\mathrm{U}_{3} \mathrm{O}_{8}$ where a coal-fired plant and an LWR on the once-through cycle have the same total power cost. For the assumptions listed above, and for current $\mathrm{U}_{3} \mathrm{O}_{8}$ prices of about $\$ 40 / 1 \mathrm{~b}$, nuclear is cheaper than coal when coal is more than about $\$ 18 / S T$. If $U_{3} 0_{8}$ should $r$ ise to $\$ 100 / 1 \mathrm{~b}$, nuclear would still be cheaper than coal for coal prices greater than about $\$ 28 / \mathrm{ST}$. Therefore, the levelized power cost of a nuclear plant is not nearly as sensitive to the cost of $\mathrm{U}_{3} \mathrm{O}_{8}$ as the levelized power cost of a coal plant is to the price of coal. It takes a $13.2 \$ / 1 \mathrm{~b}$ increase in the price of $\mathrm{U}_{3} \mathrm{O}_{8}$ to increase the total power cost of an LWR-OT by $1 \mathrm{mill} / \mathrm{kWh}$. For comparison it only takes a $2.2 \$ / \mathrm{ST}$ increase in the price of coal to increase the total power cost of a coal plant by $1 \mathrm{mill} / \mathrm{kWh}$.

\section{Results}

Figure 12 compares the total power cost of the classical FBR cycle with the LWR-OT cycle. The total power cost of the LWR-OT cycle is shown for three $U_{3} 0_{8}$ prices: $19.8 \mathrm{mills} / \mathrm{kWh}$ for $\$ 40 / 1 \mathrm{~b}, 24.3 \mathrm{mills} / \mathrm{kWh}$ for $\$ 100 / 1 \mathrm{~b}$, and $28.9 \mathrm{mills} / \mathrm{kWh}$ for $\$ 160 / 1 \mathrm{~b}$ of $\mathrm{U}_{3} \mathrm{O}_{8}$. This is to be compared with 25.5 $\mathrm{mills} / \mathrm{kWh}$ for the classical FBR system. Therefore, for the assumptions used in this analysis, the LWR-OT cycle is less expensive than the classical FBR system until $\mathrm{U}_{3} \mathrm{O}_{8}$ reaches about $\$ 110 / 1 b$.

There are two principal reasons why the FBR cycle is more expensive than the LWR-OT cycle for low uranium prices. The first reason is the high FBR capital cost. The capital cost component of the LWR is $11.0 \mathrm{mills} / \mathrm{kWh}$ whereas the capital cost component of the FBR is $15.3 \mathrm{mills} / \mathrm{kWh}$. The second reason is the increased handling costs for fuel containing plutonium. The total of the front-end and back-end fiuel-handling charges for the plutonium-fueled reactors is about 4.2-4.3 mills/kWh compared to $1.1 \mathrm{mills} / \mathrm{kWh}$ for the LWR-OT reactor. 

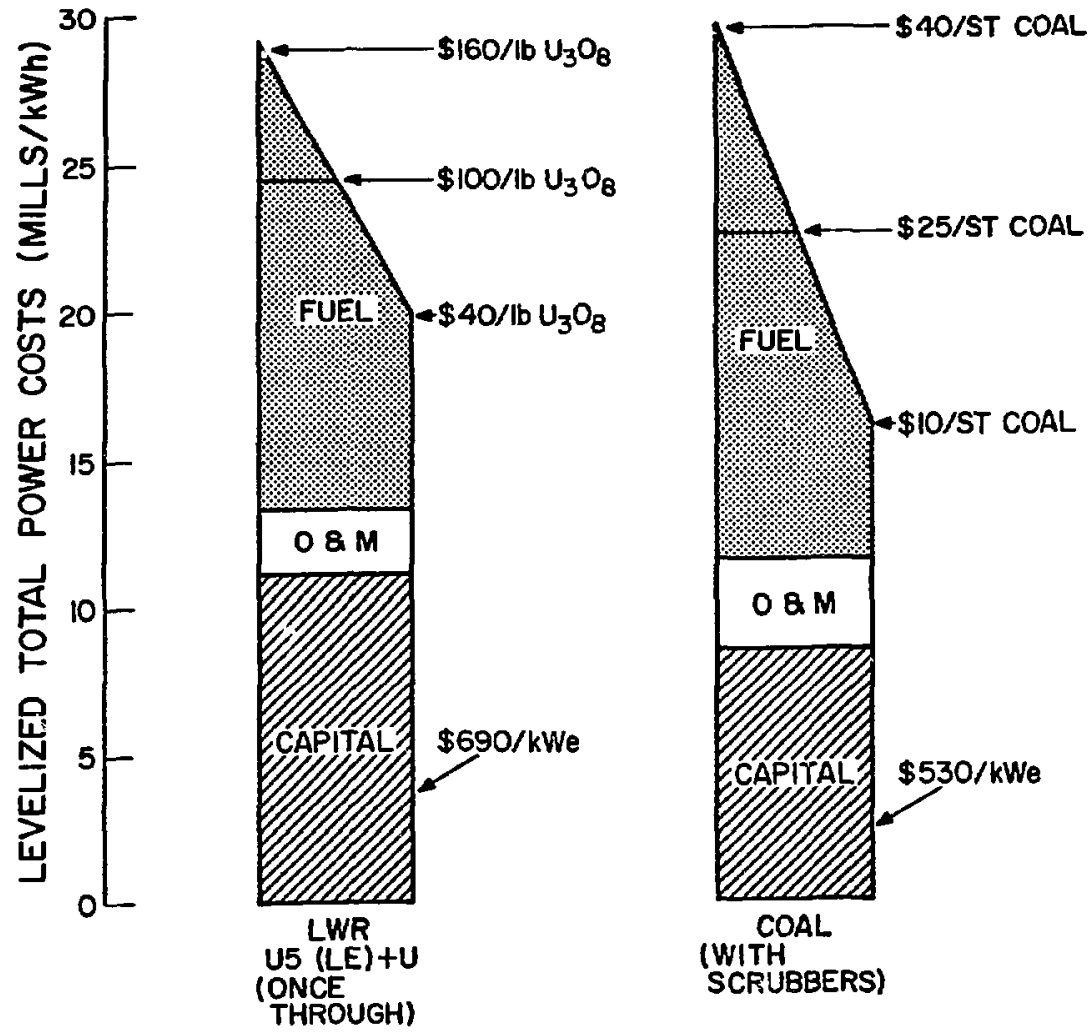

Fig. 10. Comparison of total power cost components for a coal plant with a light-water reactor on the once-through cycle.

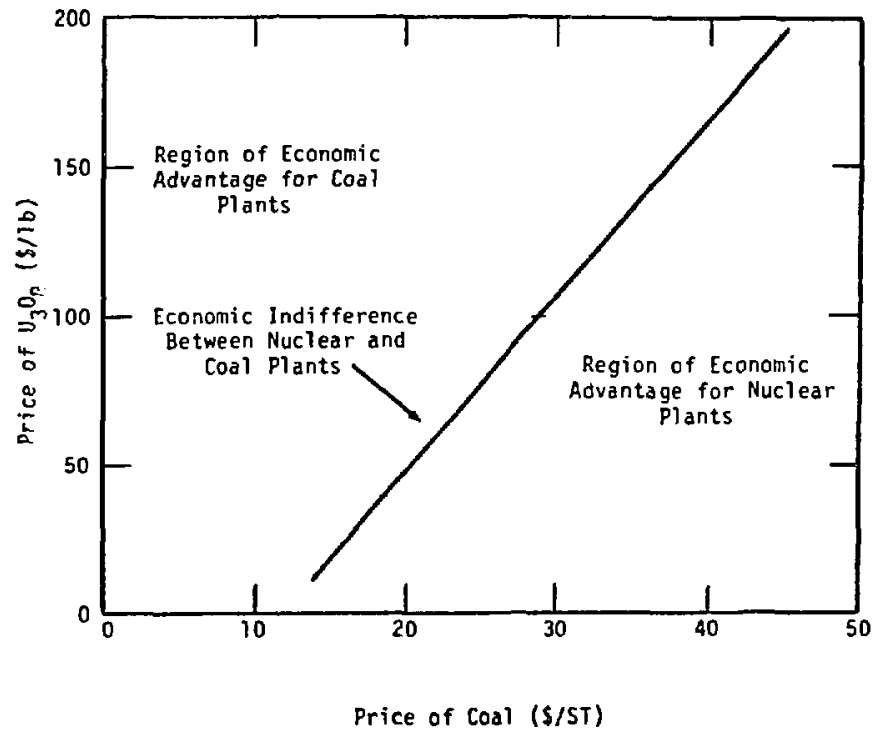

Fig. 11. Economic indifference between nuclear and coal plants. 

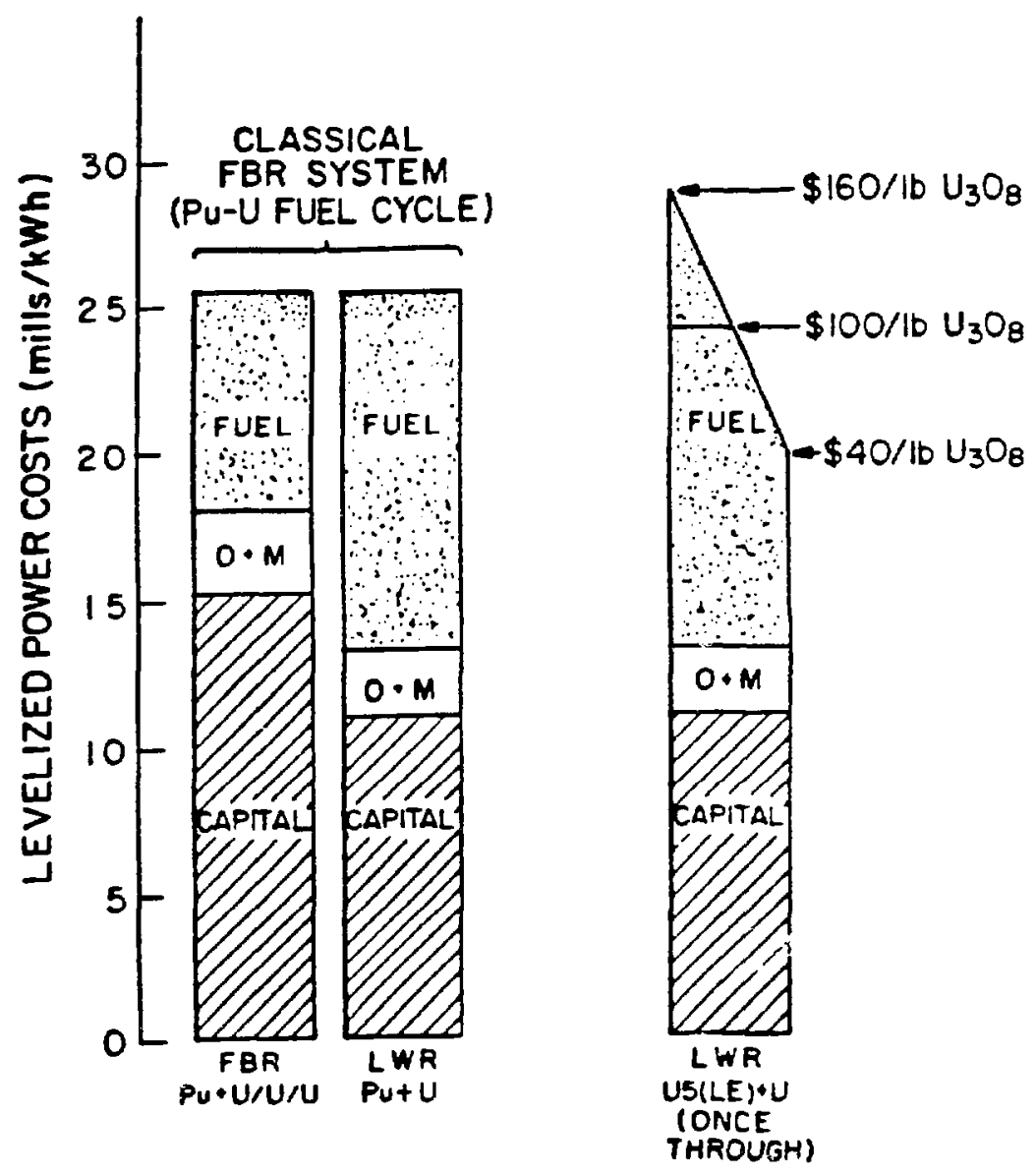

Fig. 12. Levelized power costs (mil1s/kWh).

Figure 13 compares the total power cost of the symbiotic FBR cycle with the LWR-OT cycle. The total power cost of the symbiotic FBR cycle is 24.9 mills/kWh. Therefore, the LWR-OT cycle is less expensive than the symbiotic $F B R$ cycle until $U_{3} O_{8}$ reaches about $\$ 105 / 1 b$.

Comparing the symbiotic FBR cycle with the classical FBR cycle, the classical FBR cycle is about $0.6 \mathrm{mills} / \mathrm{kWh}(\approx 21 / 2 \%)$ more expensive. There are two compensating effects that account for the total power cost of these systems being nearly equal. First, the increased handling costs for fuel containing ${ }^{233} \mathrm{U}$ compared to fuel containing plutonium make the symbiotic systems more expensive. On the other hand, the fact that ${ }^{233} U$ is a better thermal reactor fuel than plutonium from a neutronics viewpoint makes the symbiotic system less expensive. 


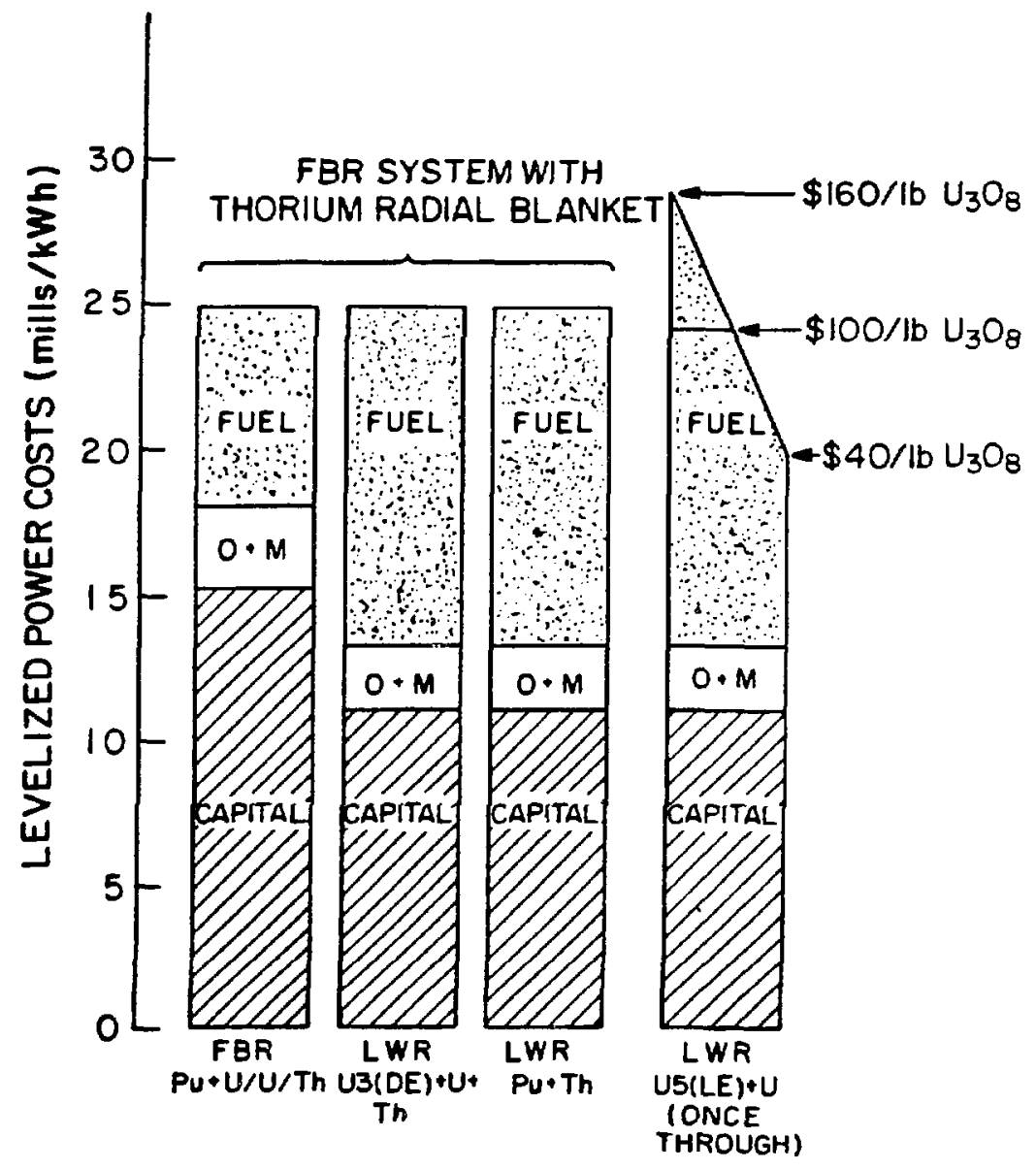

Fig. 13, Levelized power costs (mills/kWh).

VII. TECHNOLOGICAL EVALUATION

In assessments of the type presented in this report, we of ten must compare technologies that are at vastly different states of readiness. Some options such as the LWR-OT cycle are already in use and are well understood. other candidates are in an advanced state of development but have not been used commercially. Still others have only received limited testing and have great uncertainties associated with them. Although we cannot reconcile these differences in this report, we can identify the technological problems and examine their severity. This type of question is addressed in the next section (VII. A).

The attractiveness of technologies can often var greatly with changes in certain key parameters. In order to make comparisons among the fuel cycles, 
we were forced to choose a reference set of values for these important variables. In Section VII, B, we examine variations in those properties of each fuel cycle that have the greatest impact in determining its attractiveness.

\section{A. Technological Uncertainties}

The state of readiness of competing technologies is an important point of comparison. Given two options that are nearly equivalent in other respects, a decisionmaker would be wise to avoid the costs and uncertainties associated with pursuing the less mature technology. Even a clearly superior technology can lose opportunities to an inferior one if the latter is ready when the need arises or when the capital becomes available.

The principal development requirements for each fuel cycle are listed in Table IX. The relative degree of difficulty involved is represented by vertical position in the columns.

The LWR-OT cycle is plagued by the thoroughly studied, but as yet unsolved, problem of waste management. To address adequately the technical and political aspects of this problem would be beyond the scope of this study. However, unless a satisfactory solution can be found, no nuclear fuel cycle wi 11 be able to operate.

The classical FBR system faces two additional obstacles. Development of the fast breeder reactor (FBR) is proceeding at a reasonable pace. Given the success of demonstration programs, particularly in France and Germany, there is little doubt that the plutonium breeder could be available comercially in the near future. The major uncertainty is whether public sentiment and political initiatives will impede the European program. Implementation of the classical FBR cycle will also require modifications to the PUREX method of reprocessing, to handle the high plutonium content of FBR fuel.

The symbiotic FBR cycle faces a much more uncertain future. In addition to the problems associated with the classical FBR cycle, the symbiotic cycle requires an extensive program of research, development and demonstration in the use of thorium fuels. The chemical techniques for reprocessing fuels with high concentrations of plutonium, thorium, and uranium are still in the research and development stage. Commercialization of this process (PU-THOREX) would require a major development program. Even the THOREX method for reprocessing mixtures of thorium and uranium has not been demonstrated under realistic conditions. 
TABLE IX

DEVELOPMENT NEEDS OF THE FUEL CYCLES

LWR-OT

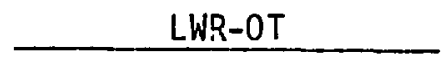

- Waste management

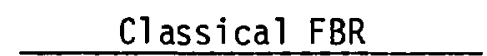

- FBR commercialization

- Waste management

- PUREX modifications
Symbiotic

- PU-THOREX R and D

- THOREX demonstration

- FBR commercialization

- Waste management

- PUREX modifications

- Remote fabrication of Th-233U fuels

- Physics of Th-fueled LWR

Other requirements, such as the development of remote fabrication of thorium and $233 \mathrm{U}$ fuels and redesign of LWRs for thorium-based fue $1 \mathrm{~s}$, present relatively minor difficulties.

The problems associated with these fuel cycles are not fundamental questions of feasibility. The development programs discussed above are almost certain to be successful if we commit sufficient resources to the effort. The major uncertainties are in the amount of $t$ ime and money required. There is also the question of whether the nation is willing to undertake the necessary development programs.

The LWR-OT cycle is the best understood. If this cycle were not so limited in its resource utilization, there :.suld be iittle incentive to develop the other two cycles. Of the two long-term options, the classical FBR is far closer to commercial status. Cormercialization of the symbiotic cycle would require a substantial additional development program in the use of thorium fuels. The symbiotic cycle would have to have some significant advantage over the classical FBR to justify this commitment.

B. Performance Parameters

A nuclear fuel cycle, like any other system, is not a static concept. There are tradeoffs and improvements that can be made to optimize the 
performance of the system. The incentive for improving a given parameter is a product of two factors: the range over which the parameter can vary and the sensitivity of fuel cycle performance to variations within that range. In the discussion that follows, we will concentrate on situations in which this combination of factors can alter significantly the attractiveness of a fuel cycie.

The continued health of the LWR-OT cycle is most strongly dependent on its utilization of the uranium resource. The effect of resource limitations on the economics of this cycle, and consequently on its life expectancy, have been discussed in Secs. $V$ and VI above. The net energy potential, which is a measure of resource utilization, has been defined above as a product of fuel cycle efficiency and uranium utilization fraction. The efficiency of the reference LWR-OT cycle is about 93\%, leaving little room for improvement. However, the uranium utilization fraction is only 0.0052 . Clearly this cycle would benefit greatly from the discovery of new uranium deposits, but there are also improvements to the cycle itself which would help.

Perhaps the most promising is the development of advanced methods of isotope separation (AIS) that can efficiently and inexpensively extract a higher fraction of the ${ }^{235} U$ from natural uranium. In our reference case the tails assay, which is the ${ }^{235} U$ content of the residue from enrichment plants, is $0.2 \%$. This represents $23 \%$ of the available ${ }^{235} U$. The new enrichment technologies could cost-effectively lower the tails assay to $0.05 \%$. This would lead to an increase of $22 \%$ in uranium resource utilization. Furthermore, the AIS technologies could raise the fuel-cycle efficiency from $93 \%$ to $96 \%$, even with the increase in separative work required to lower the tails assay. Meeting the same increased requirements for separative work with the current gaseous diffusion plants would lower the fuel-cycle efficiency to $89 \%$.

A second strategy for increasing the uranium utilization fraction of the LWR-OT cycle is LWR upgrading. This encompasses a variety of measures including new fuel management practices, restructuring of the lattice, and changes in operating procedures. It is estimated that these improvements could increase uranium utilization by 15 to $30 \%$. Any improvement in the mining and milling of low-grade uranium would also be a boon to the LWR-OT cycle.

Although a combination of these improvements can enhance the economics and ext $\mathrm{id}$ the lifetime of the LWR-OT cycle, they cannot alter the fact that it is a short-term energy option. Their importance lies in their ability to 
buy extra time while long-term electrical energy sources are being developed and refined.

The classical FBR and symbiotic cycles are not sensitive to incremental changes in uranium utilization. However, the economics of these cycles are very important and very uncertain, considering the number of new technologies required. Total power costs for these cycles will be most sensitive to the capital cost of breeder reactors and the costs of reprocessing and refabrication services. These factors have been discussed in detail in Sec. VI.

Proliferation resistance is also an important issue that can be affected in several ways by technological developments. These questions are treated in detail in Sec. VIII.

Finally, the breeding ratio of the FBR can be an important parameter because it affects the speed with which the breeder can produce plutonium. A breeding ratio that is only slightly greater than unity would be sufficient for steady-state operation of either the classical FBR or symbiotic cycle. But when these cycles are beginning operation, a great deal of plutonium will be required to fuel high-inventory first core loadings. Because the breeders will be the principal sources of this plutonium, the breeding ratio will be the limiting factor in the growth rate for each cycle.

\section{INSTITUTIONAL ISSUES}

The purpose of this section is to examine the legal, political, and social factors that can affect the ability of a technology to penetrate the market. For all technologies, this would include safety and occupational health problems, and their effect on the licensing process. There are also factors that determine the commercial potential of a technology. These include the reliability of the equipment, ease of operatior. difficulties associated with financing, and the appropriateness of the technology for meeting the real needs of society. In the case of nuclear facilities there is the additional, almost overriding, concern over the proliferation of nuclear weapons.

Issues of this type are difficult to assess in an objective fashion. We have tried to avoid personal biases by developing our criteria before addressing any of the fuel cycles. This approach has led us to some conclusions that deviated greatly from our initial intuitions. However, the reader should be aware that subjectivity can never be eliminated completely. 
The growing worldwide problem of nuclear arms development has become an increasingly important issue in international affairs. Nuclear weapons states have continued to maintain and increase their arsenals, despite attempts at arms control. With the widespread dissemination of nuclear technology, the emergence of additional nuclear weapcris states cannot be ruled out. There is also concern over the possible acquis ion of nuclear materials or nuclear weapons by terrorist groups.

In this context the peaceful uses of nuclear energy have come under close scrutiny. It has been recognized that a peaceful nuclear power program can be a source of materials, facilities, and expertise critical to the acquisition of a nuclear weapons capability.

However, some nuclear fuel cycles are more resistant to this type of abuse than others. Our goal in this analysis is to compare the proliferationresistant qualities of alternative fuel cycles. For the purpose of this discussion we define proliferation as

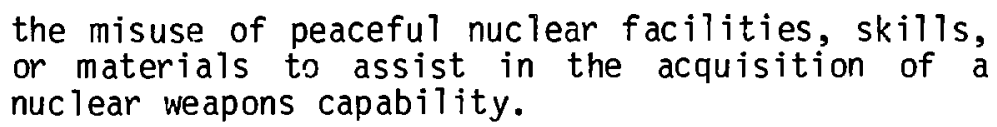

Our primary concern is the acquisition of nuclear weapons by national governments. Abuse of the fuel cycle by terrorist groups is a much easier probiem to cope with.

It must be recognized that no fuel cycle can be proliferation-proof. There is no way of preventing the abuse by a national government of fuel-cycle facilities within its boundaries. But fuel cycles should be designed so that an attempt to proliferate can be detected in time for the international community to respond in some appropriate fashion.

We apply three types of criteria to each fuel cycle considered. First we identify those aspects of the cycle that represent a significant proliferation risk. This criterion must be applied to the cycle in its simplest state, before any proliferation-resistant measures have been applied. Next we enumerate the types of proliferation barriers that would be necessary. Finally, we examine the ways in which a proliferator might be able to circumvent the barriers. 
1. Proliferation Risks. The task of identifying the real proliferation risks of a fuel cycie is a difficult one. If we find danger in every aspect of the cycle, the important distinctions between fuel cycles will be blurred. On the other hand, if we ignore a real threat, the analysis will be distorted.

One useful concept is that of "background" risk, or the risk that would exist if there were no fuel cycle. For instance, there are 1 arge supplies of natural uranium throughout the world. To convert this material to a nuclear explosive would require an isotope enrichment capability. We do not attach any risk to a fuel-cycle material that requires enrichment, because such a material is not qualitatively different from natural uranium. The fact that some materials require less enrichment than natural uranium is only of secondary importance. Once a proliferator has obtained an enrichment capability, the amount of separative work required will not make a significant difference.

We are also not concerned with those features that are common to all fuel cycles. For instance, he assign no risk to spent fuel. We have identified two types of materials and two types of facilities as significant proliferation risks.

In classifying fuel-cycle materials, the principal criterion is the degree of difficulty involved in converting it to nuclear explosives grade (Table $x)$. Material directly usable for weapons production is labeled as "red," the most dangerous.* This includes chemically pure high-enriched uranium (HEU) or plutonium (Pu). If the HEU or plutonium is diluted in a chemically similar element, the mixture is classified "orange." Because these mixtures require only simple chemistry for conversion to weapons material, no qualitative distinction is made between "red" and "orange" materials. Fuel-cycle materials that require reprocessing or enrichment for conversion to weapons grade are considered "green." No proliferation risk is assigned to such mixtures.

A fuel-cycle facility is considered a proliferation risk only if it is capable of converting a "green" mater ... to a "red" or "orange" material. According to this criterion, only enrichment and reprocessing are considered as risks.

The proliferation risks of fuel cycles are presented schematically in Fig. 14 .

太The classification of heavy metal materials by colors follows the example of Wohlstetter et al. in Ref. 15. 


\section{TABLE $X$}

PROL IFERATION POTENTIAL OF FUEL CYCLE MATERIALS

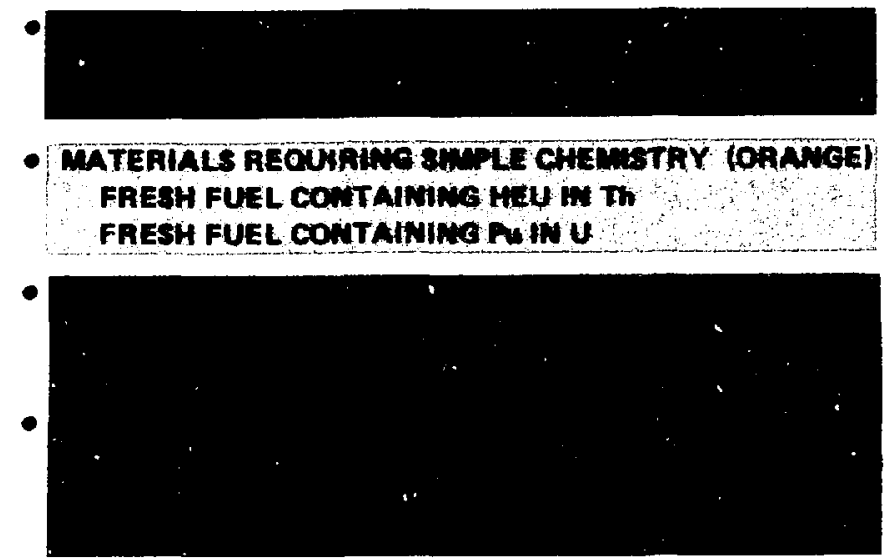

2. Proliferation Barriers. A second measure of proliferation-resistance is the amount of effort that will be necessary to mitigate the risks described above. Three types of barriers to proliferation. can be constructed: technical measures, safeguards, and political arrangements.

Technical barriers are engineering solutions to the proliferation problem. For proliferation-sensitive materials, an effective measure would be one which converts a "red" or "orange" material to a "green" one. For HEU the most effective barrier would be isotopic denaturing with ${ }^{238} \mathrm{U}$. Denaturing is not effective for plutonium, however, because any mixture of plutonium isotcpes is usable for weapons production.* The addition of a radiation barrier to plutonium would be effective because the resulting mixture would require reprocessing to recover the plutonium. Radiation barriers can be implanted by incomplete reprocessing, spiking, or post-irradiation.

Safeguards measures include material accountancy and containment/ surveillance (c/s) activities. Accountancy involves the careful measurement of all sensitive materials in process, in transit, or in stocks. Despite the existence of extremely precise on-line monitoring devices, current accountancy techniques are limited to an uncertainty of about $0.5 \% .16$ Given the large throughputs of heavy metals contemplated for future fuel-cycle facilities, a

*A1though there are definite advantages to having a high percentage of plutonium-239. 


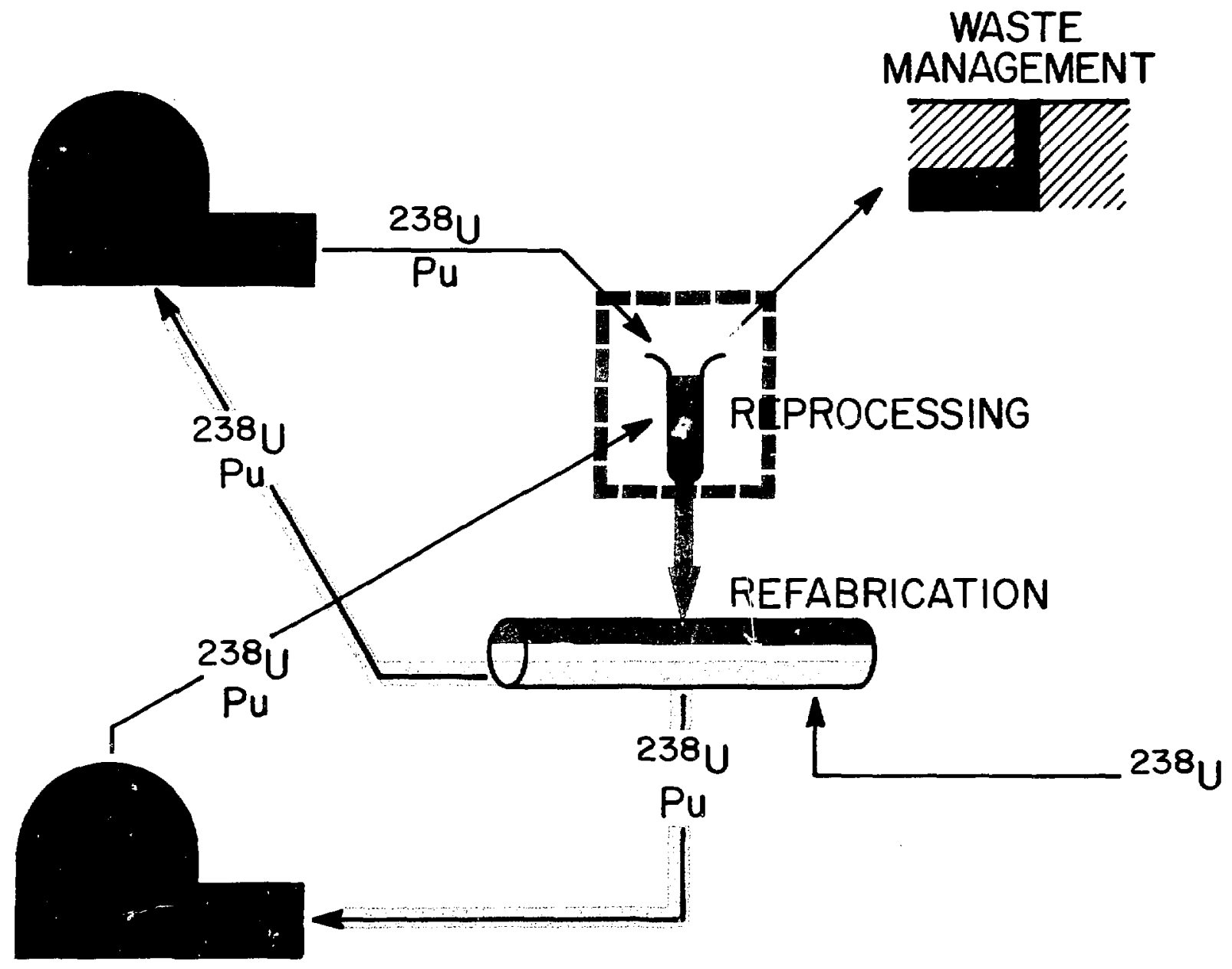

- materials directly usable

PURE HEU ( $235 \mathrm{U}$ OR ${ }^{233} U$ )

PURE PU (WEAPON OR REACTOR GRADE)

- MATERIALS REQUIRING SIMPLE CHEMISTRY

FRESH FUEL CONTAINING HEU IN Th

FRESH FUEL CONTAINING PU IN U

- PROLIFERATION-SENSITIVE TECHNOLOGIES

REPROCESSING

ENRICHMENT

Fig. 14. Proliferation potential of nuclear fuel cycles. 
proliferator could divert enough naterial for several nuclear weapons without being detected. Furthermore, because some accountancy techniques depend on detection of characteristic radiation from the safeguarded material, the presence of uncertain radiation sources in the sample would further degrade the precision. This would be a problem for "spiked" plutonium and fuels containing $233 \mathrm{U}$. For these reasons, accountancy must be recognized as a necessary, but not sufficient, deterrent to the diversion of proliferation-sensitive materials.

Accountancy can be supplemented effectively by an array of strategies we loosely classify as containment/surveillance measures. The purpose of such measures is to detect and, if possible, deiay unauthorized access to sensitive materials and facilities. This category includes security forces, access monitoring, physical barriers, and a variety of other design features and operating procedures.

To ensure the effectiveness of the technical and safeguards barriers mentioned above, political arrangements will have to be negotiated. Whether they come in the form of international treaties, multilateral contractual agreements, or guidelines imposed by nuclear suppliers, these arrangements will involve an encroachment on the soveraignty of user nations. Because suci measures will be difficult to impose, it would be desirable to develop fuel cycles that require as few of these arrangements as possible.

3. Routes to Proliferation. A final test of proliferation resistance is the variety of opportunities that the fuel cycles present for potential proliferators. These routes to proliferation might include overt actions such as the seizure of a facility or confiscation of sensitive material. Covert means such as diversion of materials, circumvention of barriers, or misuse of facilities also need to be considered. There are also indirect effects such as the transfer of expertise concerning sensitive technologies.

4. Results. The criteria we apply in comparing proliferation potential are summarized in Table XI. The first step in the analys is is to tabulate the risks, barriers, and routes to proliferation as shown in Tables XII to XIV. obviously there is a great deal of redundancy in these tabuiations. The potential danger from diversion of ${ }^{23} U$ and the need to denature ${ }^{233} U$ are not separate issues. Even more obvious is the fact that fuel cycles cannot be judged by comparing the number of red blocks in each column. The final analysis requires a critical look at the three tables. 
The LWR-0T cycle has the fewest proliferation problems, all of which are associated with enrichment facilities. Dealing with this single problem area should be a relatively tractable goal.

The classical FBR cycle faces an entirely different set of issues associated with reprocessing facilities and plutonium. The catalog of necessary barriers presents a much more formidable task for fuel-cycle designers, facility operators, and the international comunity. A transition from the LWR-OT cycle to the classical FBR cycle would represent a qualitative increase in proliferation potential.

The symbiotic cycle has all the problems of the classical FBR cycle and several additional problems related to ${ }^{23} \mathrm{U}$. Whereas these additional difficulties do not constitute an overwhelming argument against the symbiotic cycle, they are serious enough to be considered when choosing between the two cycles.

Although the LWR-OT cycle is clearly the most desirable from a proliferation perspective, the fact remains that it represents a short-term source of electrical energy. In a comparison of the two long-term options considered in this study, the classical FBR cycle has definite advantages over the symbiotic cycle. The latter conclusion is surprising in light of the fact that the symbiotic cycle was first proposed as a proliferation-resistant alternative to the classical breeder cycle. The following discussion points out some of the differences in perspective that nave led to the opposite conclusion.

One important difference is in our perception of denatured fuel. Advocates of the symbiotic cycle emphasize that denatured fuel is almost equivalent to the low-enriched fuels used in current reactors insofar as a potential proliferator would need an isotopic enrichment capability to convert it to weapons material. We concur with this appraisal. However, from our perspective, the pure ${ }^{233} U$ that exists after reprocessing is a weapons-usable material that must be safeguarded. Denaturing is a technical barrier that must be applied and verified, not a condition that naturally exists.*

Another important distinction is the fact that we equate "spiked" plutonium fue 15 with denatured $233 U$ fuels, with respect to proliferation resistance. This assumption is based necessarily on the postulate that enrichment

*In some thorium-based fuel cycles, the $233 \mathrm{U}$ is denatured at all times, but this is not true for the symbiotic cycle. 


\section{TABLE XI}

\section{PROLIFERATION CRITERIA}

- Proliferation Risks

- Materials:

$\mathrm{Pu}$ and HEU

- Facilities:

Enrichment and Reprocessing

- Proliferation Barriers

- Technical Measures

- Safeguards

- Political Arrangements

- Routes to Proliferation

- Overt

- Covert

- Indirect

TABLE XII

PROLIFERATION RISKS

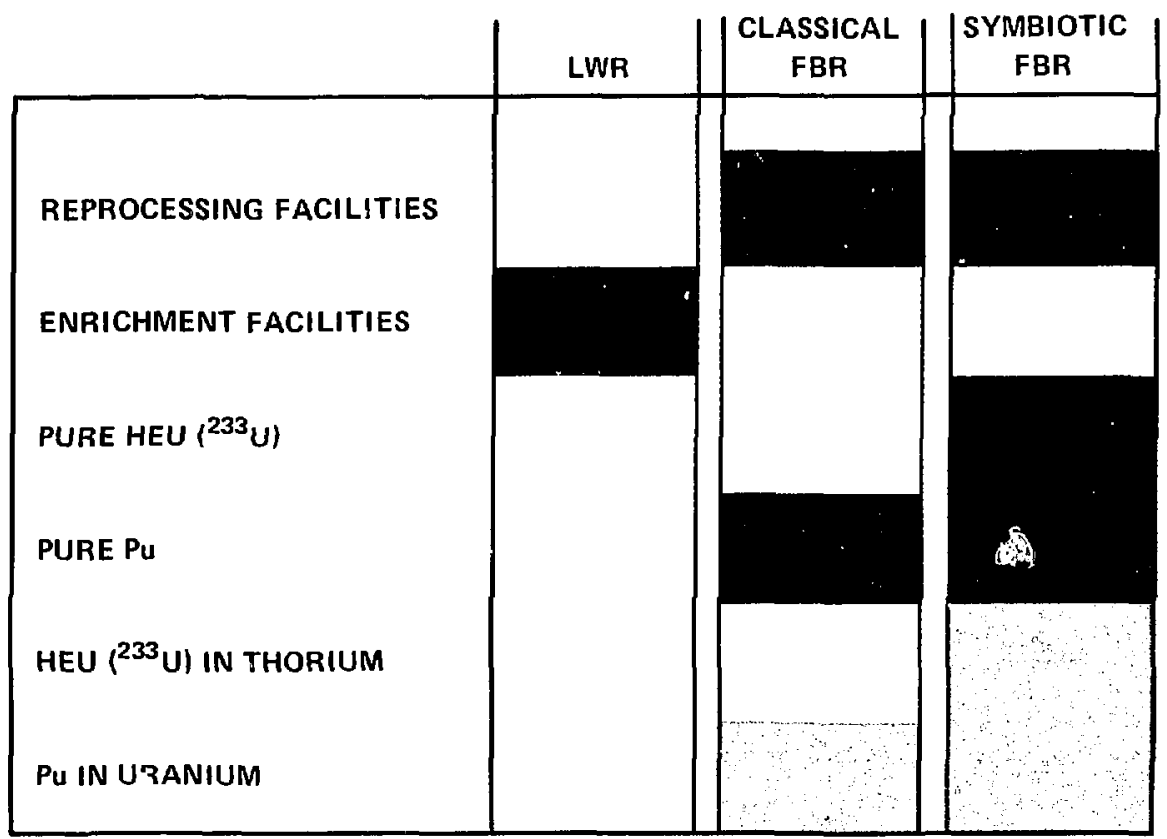




\begin{tabular}{|c|c|c|c|c|}
\hline & & LWR & $\underset{\text { FBR }}{\text { CLASSICAL }}$ & $\begin{array}{l}\text { SYMBIOTIC } \\
\text { FBR }\end{array}$ \\
\hline \multirow{2}{*}{ TECHNICAL: } & ISOTOPIC DENATURING & & & \\
\hline & $\begin{array}{l}\text { RADIATION BARRIER } \\
\text { FOBPTI }\end{array}$ & & & \\
\hline \multicolumn{4}{|c|}{ SAFEGUARDS: ACCOUNTANCY } & \\
\hline \multirow{3}{*}{\multicolumn{5}{|c|}{$\begin{array}{c}\text { OF }{ }^{233} \mathrm{U} \\
\text { OF Pu } \\
\text { CONTAINMENT/SURVEILLANCE } \\
\text { OF REPROCESSING }\end{array}$}} \\
\hline & & & & \\
\hline & & & & \\
\hline & OF ENRICHMENT & & & \\
\hline \multicolumn{5}{|c|}{$\begin{array}{l}\text { INSTITUTIONAL: } \\
\text { CONTROL/OVERSIGHT } \\
\text { OF REPROCESSING }\end{array}$} \\
\hline \multicolumn{5}{|c|}{ OF ENRICHMENT } \\
\hline \multicolumn{5}{|c|}{$\begin{array}{l}\text { VERIFICATION } \\
\text { OF DENATURING }\end{array}$} \\
\hline \multicolumn{5}{|c|}{ OF PU RADIATION BARRIER } \\
\hline & CONTROL OF REPROCESSING & & & \\
\hline & & & & \\
\hline & $\begin{array}{l}\text { CONTROL OF ENRICHMENT } \\
\text { TECHNOLOGY TRANSFER }\end{array}$ & & & \\
\hline
\end{tabular}

technology is as readily available to a potential proliferator as is reprocessing technology. Many analysts would argue that this is still not the case, in spite of recent developments in centrifuge technology.

The symbiotic cycle is almost always analyzed in the context of a particular institutional arrangement in which plutonium-fueled reactors are placed in a secure area and denatured reactors are located outside the secured area. In our analysis fuel cycles are first examined in the absence of safeguards, technical barriers, and institutional arrangements. Such modifications are 
TABLE XIV

ROUTES TO PROLIFERATION

\begin{tabular}{|c|c|c|c|}
\hline & LWR & $\begin{array}{c}\text { CLASSICAL } \\
\text { FBR }\end{array}$ & $\begin{array}{c}\text { SYMBIOTIC } \\
\text { FBR }\end{array}$ \\
\hline \multicolumn{3}{|l|}{$\begin{array}{c}\text { CONFISCATION OR DIVERSION } \\
\text { OF } 233 \mathrm{U}\end{array}$} & \\
\hline \multirow{2}{*}{\multicolumn{4}{|c|}{$\begin{array}{c}\text { OF Pu } \\
\text { HOST COUNTRY SEIZURE OF } \\
\text { REPROCESSING }\end{array}$}} \\
\hline & & & \\
\hline \multicolumn{4}{|l|}{ ENRICHMENT } \\
\hline \multicolumn{4}{|l|}{$\begin{array}{l}\text { COVERT CIRCUMVENTION OF } \\
\text { 233 U DENATURING }\end{array}$} \\
\hline \multicolumn{4}{|l|}{ COVERT CIRCUMVENTION OF } \\
\hline \multicolumn{4}{|c|}{$\begin{array}{l}\text { COVERT MISUSE OF ENRICHMENT } \\
\text { FACILITY TO PRODUCE HEU }\end{array}$} \\
\hline \multicolumn{4}{|l|}{$\begin{array}{l}\text { TRANSFER OF REPROCESSING } \\
\text { EXPERTISE }\end{array}$} \\
\hline $\begin{array}{l}\text { TRANSFER OF ENRICHMENT } \\
\text { EXPERTISE }\end{array}$ & & & \\
\hline
\end{tabular}

added only as necessary to reduce proliferation potential. Because institutional arrangements invariably involve an encroachment on national sovereignty, we prefer fuel cycles that require as few of them as possible. In our analysis, placing reactors in a secure area could be considered superfluous. Furthermore, because of our assumption about the equivalence between spiked plutonium and denatured ${ }^{233} U$, our analysis would show no preference for securing one type of reactor rather than the other.

Finally, if evaluated in terms of "secure" and "less secure" nations, the symbiotic cycle has an additional, probably fatal, fiaw. Although this analysis considered time-independent systems in equilibrium, the route to equilibrium is also important. The reason is that the goal of the symbiotic cycle is to produce denatured ${ }^{233} \mathrm{U}$ for "less secure" nations. 
Equilibrium probably would be reached by reprocessing the plutonium currently being produced by LWRs and loading this plutonium in FBRs with thorium blankets. It would take several decades before enough ${ }^{233} U$ could be produced to deliver more than a token amount to "less secure" countries. It is unlikely that these nations would be willing to wait several decades after the classical FBR is available commercially.*

B. Health, Safety, and the Environment

The impact of large energy facilities results from their consumption of valuable resources and production of toxic substances. For nuclear facilities it is important to distinguish between radiological and chemical toxins.

1. Resource Requirements. The most important resources used in the nuclear fuel cycle are land, water, and construction materials. ${ }^{17}$

The 1 and requirements, which are dominated by those of the reactor site, vary by only a small fraction from one fuel cycle to another. Furthermore, they are comparable to, and in some cases less than, the land requirements of alternative sources of electrical energy.

Water consumption in the fuel cycles is dominated by the cooling water requirements of the reactors. Although the cooling needs of nuclear reactors are comparable to those of other electrical generating stations, the large size of the nuclear plants can lead to more severe local impacts on water supply. However, advanced cooling methods such as the dry or hybrid systems can be designed to achieve any desired water conservation level and thus mitigate the local impact.

There probably will be a minor difference in the water requirements of the three fuel cycles considered in this study. Because the liquid metal fast breeder reactor (LMFBR) is expected to run at a higher thermal efficiency than the LWR, it would discharge less waste heat for the same amount of electrical output. This would result in somewhat reduced water requirements for the classical FBR and symbiotic cycles.

Construction of reactors and other nuclear facilities requires the use of metals that are classified as "critical and strategic materials."18 Shortages of these materials could affect the nuclear industry. However, it is not likely that the small amounts used in the nuclear fuel cycle would contribute significantly to such shortages.

*France is already in the earin $7 y$ stages of marketing the SUPER-PHENIX, which is an FBR on the plutonium-uranium cycle. 
The worst case is for nickel. If we built 20 new nuclear reactors every year, the installed nuclear capacity would eventually level off at 600 GWe. That would be more than enough capacity to meet all of this nation's current electrical needs. A building effort of that magnitude would increase our annual consumption of nickel by 5 to $10 \%$. Increases in the consumption of other critical materials would be $1 \%$ or less.

We conclude that differences in land, water and material requirements do not constitute a major factor in comparing the impacts of nuclear fuel cycles.

2. Chemical Toxicants. Chemical residuals can be classified as gaseous emissions, liquid effluents, and solid waste. Emissions of gaseous toxicants as a result of nuclear fuel-cycle activities have been shown ${ }^{19}$ to be minimal compared to an equivalent coal-fired generating facility. In fact, about 98\% of the gaseous emissions attributed to the fue 1 cycle are indirect; this is based on the postulate that enrichment facilities purchase electricity from coal-fired generators.

The substantial quantities of solid and liquid residues in mine spoils and mill tailings represent the most significant chemical toxicants in the fuel cycle. Because the tailings contain heavy metals and organics, there is concern that they could show up in water bodies or food chains. ${ }^{20}$ Under existing practices the potential environmental hazards of mine spoils and mill tailings are comparable to those of coal preparation wastes, although the actual pollutants differ. ${ }^{5}$ Proposed regulations to minimize the migration of radio-nuclides from mill tailings will likely also minimize the hazards from heavy metals and organics, but mine spoils still must be considered. In addition, a transition from the LWR-OT cycle to the long-term cycles would eliminate the need for mining, milling, and enrichment, the principal sources of chemical toxicants.

3. Radiological Hazards. Evaluating the radiological hazards associated with nuclear fuel cycles is a complicated problem involving several sources of uncertainty. 21

The effects of large doses of radiation administered over short periods of time have been studied extensively by using data from radiation accidents, medical irradiations, and nuclear weapons. The principal health problem is an increased risk of cancer and genetic defects. What is not nearly so well understood is the impact of small doses administered to a large population over long time periods. Current estimates are that an exposure of $10^{6}$ 
person-rem will result in 150 additional cancer deaths and 10 occurrences of genetic defects. 21 Because of the assumptions used in deriving these estimates, they generally are regarded as upper limits to the actual risk.

It is instructive to compare these estimates with the background radiation we receive from cosmic rays, building materials, food, the ground, and the air we breathe. Each American receives from 0.1 to 0.17 rem per year from such sources, which means that the 217 million people in this country accumulate a total annual dose of about $30 \times 10^{6}$ person-rem. According to the risk estimates, this background radiation would produce about 4,500 additional cancers and 300 occurrences of genetic defects annually. Because this could represent on $7 y 1.1 \%$ of a 11 cancers and 1 ess than $0.1 \%$ of a 11 genetic defects, we cannot verify or disprove these predictions.

Standards for radiation dose limitations are compailible with background exposures. The general public is limited to an average annual dose of 0.17 rem, with a maximum individual dose of 0.5 rem in any one year. Limits for occupational exposure are less stringent because the population of persons exposed is smaller. Whole body doses for radiation workers are limited to 5 rem in any one year.

Emissions of radioactive material from fuel cycle facilities cannot be estimated with great accuracy, and they will vary from one plant to another. The transport of radionuclides into the human environment is difficult to determine and certainly will depend on the local geology and climate at each site. This is especially important for isotopes that must be inhaled or ingested to do damage.

Several investigators have attempted to assess the health impacts of nuclear power (see Refs. 18, 19, 22, and 23). Although these studies addressed different fuel cycles and used different methodology, they all reached similar conclusions. These and other studies conclude that nuclear fuel cycle facilities can be operated routinely with no significant radiological hazard to the public.

A recent study by a committee of the American Physical Society ${ }^{24}$ concluded that the principal sources for public radiation exposure are reprocessing plants, uranium mines, and mills. They conclude that the hazards associated with reprocessing and recycling are outweighed by the resultant reduction in risks from mining and milling. This conclusion agrees with the findings 
cited in Ref. 22. In the comparison of alternative fuel cycles, these findings would tend to favor the two long-term options over the LWR-OT cycle.

There are large uncertainties inherent in estimating the public radiation hazard from the nuclear fuel cycle. The results of several studies indicate that the overall danger is well below the risk from natural sources. Because of the large margin for error in these estimates, we believe it is safe to conclude that nuclear fuel cycles can be operated without endangering public health.

Comparisons of radiation hazards among fuel cycles cannot be made with great confidence. Operation of real facilities can deviate drastically from the estimates used in studies. Although there appears to be some advantage in converting from the LWR-OT cycle to the long-term options, uncertainties are too large to consider this a well-founded conclusion.

The issue of reactor safety will be a deciding factor in the future of nuclear energy. Engineering studies of the probability and consequences of accidents have been performed for both the LWR ${ }^{25}$ and the LMFBR. ${ }^{26}$ In both cases, risk is dominated by low-probability, high-consequence accidents involving release of 1 arge fractions of the core inventory of fission products and fuel materials into the environment. These accidents involve catastrophic whole-core disruption and subsequent failure of systems designed to prevent the escape of radioactive materials. For both LMFBRs and LWRs, the probability of occurrence of these accidents is too low to measure statistically and can only be estimated. Uncertainty limits on the estimates are wide and overlap for LMFBRs and LWRs.

The probability estimates for the high-consequence accidents involve the likelihood of multiple equipment failures and unusual or unexpected physical behavior because the possibility of highly energetic thermal, chemical, or nuclear reactions cannot be precluded. Although it is considered unlikely that such reactions would be sufficiently energetic to disrupt reactor containment, they are nonetheless theoretically possible. On the basis of these considera- tions, the LMFBR and LWR risks appear to be comparable. ${ }^{27}$ We would there- fore conclude that with respect to reactor safety there is no significant difference in the fuel cycles considered in this study.

4. Conclusions. All of the fuel cycles considered in this study can be operated in a manner that is compatible with public health and safety. There is some advantage to be gained by converting to cycles that do not require 
mining and milling of uranium. This conclusion is especially true in light of past experience with these two functions. We conclude that the long-term cycles have a small advantage over the LWR-OT cycle in their effect on public health.

C. Commercialization

Bringing a new technology successfully to market requires the complicated interplay of many actors. We can gain some insight into this process by listing the decisionmakers who are involved and examining the factors that influence their decisions.

To commercialize a nuclear fuel cycle, five types of decisions must be made:

(1) the expenditure of funds for research, development, and demonstrati on (RD\&D);

(2) industrial commitment to manufacture the reactors and to operate the fuel facilities;

(3) a decision on the part of electric utilities, with approval from state utility commissions, to operate the reactors;

(4) licensing of all facilities by the Nuclear Regulatory Commission (NRC); and

(5) public acceptance of the facilities.

The LivR-OT cycle has been in operation for two decades and, despite the potential adverse reaction to the Three-Mile Island incident, we assume for the purpose of this discussion that it will retain its comercial status. In the following sections, we compare the fuel cycles as they relate to each of the decisions listed above.

1. Research, Development, and Demonstration. The LWR-OT cycle could continue to operate without any RD\&D investment. Improvements to the cycle, such as the enhanced LWR and advanced isotope separation, can be incorporated as they become available. Research on the management and disposal of radioactive waste will continue until society is convinced that a satisfactory method is available, although opinions vary widely on how much of this research is necessary. Nevertheless, the problem of waste disposal is common to all fuel cycles.

The classical FBR cycle requires the commercialization of a breeder reactor. The liquid metal fast breeder reactor (LMFBR) has achieved an advanced 
state of development as a result of massive RD\&D programs in the United States, France, Germariy, Britain, and the Soviet Union. Research on fabrication and reprocessing of LMFBR fuels has also progressed at a satisfactory pace. Barring a major shift of emphasis, the momentum of this worldwide program will bring the LMFBR and the plutonium fuel cycle to commercial status befure the end of this century.

Commercialization of the symbiotic cycle also depends on the success of the LMFBR program. In addition, it will require a large new commitment of RD\&D funds to develop the fabrication and reprocessing methods for thorium-uraniumplutonium fuel mixtures. This extra requirement could be a formidable obstacle to the symbiotic cycle.

2. Industrial Participation. Industrial experience with nuclear energy has been disappointing. ${ }^{28}$ Reactor vendors have consistently operated at a loss in anticipation of a nuclear bonanza that has not materialized. Participants in the $\mathrm{Clinch}$ River breeder project and the Barnwell reprocessing plant have experienced the frustration of changing national priorities. Consequently an industry commitment to market any new nuclear technology will be difficult to obtain.

In a comparison of the two long-range fuel cycles, the classical FBR has some advantage in this regard. The plutonium fuel facilities represent only an evolutionary step beyond current technology as represented in the Barnwell facility. By contrast, the thorium-related facilities, which are required for the symbiotic cycle, differ significantly from current technology.

3. Electric Utility Commitment. A utility decision to purchase any type of nuclear reactor will be difficult in the years to come. Rising capital costs, long lead-times, uncertain inflationary trends, and high interest rates will motivate utility companies, state utility commissions, and public interest groups to favor less capital-intensive technologies. A utility that decides to go nuclear would tend to choose an LWR over an LMFBR because the lat.ter is more capital-intensive and more complicated to operate. This would favor continued reliance on the LWR-OT cycle.

4. Nuclear Facility Licensing. Regulations and procedures for licensing nuclear reactors and fuel-cycle facilities are always subject to change. Consequently, the licensability of fuel cycles should not be judged on the basis of the detailed regulatory guidelines in place at this time. However, the standards for licensing, as stated in the Code of Federal Regulations, ${ }^{29}$ 
will probably remain the same. The Nuclear Regulatory Commission will have to determine how each fuel cycle facility affects (1) the common defense and security, and (2) the health and safety of the public.

All nuclear fuel cycles can have a beneficial effect on national security by contributing to our domestic supplies of energy. Although these power plants are 1 arge and vulnerable to disruption in times of national emergency, the same problem exists with all centralized sources of electrical energy.

The issue of nuclear weapons proliferation and its implications for national security is likely to be a major factor in licensing decisions. The qualitative difference between the proliferation potential of the LWR-OT cycle, on the one hand, and the two long-term cycles, on the other, will probably represent a major obstacle to the transition from the LWR-OT to the long-term cycles. In the long run, the classical FBR will have some advantage over the symbiotic system because of the proliferation potential of $233 \mathrm{U}$.

It is difficult to predict what the attitude of the NRC will be concerning the health and safety aspects of nuclear power. The principal issues will undoubtedly be the safety of reactors and the long-term integrity of nuclear waste repositories. Although it is possible that nuclear energy may rise or fall on this issue, we have found no evidence to suggest that one fuel cycie should be favored over another because of differences in health, safety, and environmental impacts.

5. Public Acceptance. Active public involvement in technological issues is generally mobilized only at times when major changes are being debated. For instance, a movement to eliminate completely the nuclear power option would arouse public interest.

A transition from the current LWR-OT cycle to one or both of the longterm cycles might also be an occasion for intense public participation. Citizens would have to grapple with the implications of "breeder" reactors, "plutonium" fuels, and "reprocessing." It is not likely, however, that public initiative would be a major factor in choosing between the classical FBR and symbiotic FBR cycles.

6. Summary. The future of nuclear power rests in the hands of a diverse group of decisionmakers whose motives and methods vary greatly. The importance of each actor lies not only in the impact of his own decision, but also in the effect it will have on other decisionmakers. This "proliferation of uncertaint $y^{\prime \prime 30}$ can only lead to indecisiveness and inaction. 
There is a good chance that the LWR-OT cycle can continue to operate, in spite of the negative reaction to the Three-Mile-Island incident. The effort and money already invested in that cycle may carry it through the crisis.

The outlook for developing either of the long-term fuel cycles is not nearly so bright. The prevailing atmosphere of uncertainty, combined with the poor performance of nuclear-related investments, cannot inspire the type of massive commitment required to market a new fuel cycle. Some analysts ${ }^{3}$ have advocated a stronger government role to restore public confidence in the nuclear option. Perhaps the creation of an energy mobilization board is a step in that direction.

If a long-term nuclear fuel cycle materializes, it may be a mixture of the classical FBR and symbiotic FBR cycles. However, there are several factors noted in the discussion above that probably will combine to strongly favor the classical FBR cycle over the symbiotic FBR option.

\section{REFERENCES}

1. "Report of the Nonproliferation Alternative Systems Assessment Program," United States Department of Energy report DOE/NE-0001 (1979).

2. D. R. Haffner and R. W. Hardie, "Reactor Parameters of Alternative Fueled Fast Breeder Reactor Core Designs," Nuclear Technology 42, 123-132 (February 1979).

3. H. A. Feiveson and T. B. Taylor, "Security Implications of Alternative Fission Futures," Bulletin of the Atomic Scientists 14-18, 46-48 (December 1976).

4. G. L. Kulcinski, G. Kessler, J. Holdren, and W. Hafele, "Energy for the Long Run: Fission or Fusion?" American Scientist 67, 78 (1979).

5. T. He $\mathrm{m}$, Hanford Engineering Development Laboratory, private communication May 1979.

6. "AEC Gaseous Diffusion Plant Operations," United States Atomic Energy Commission report ORO-684 (January 1972).

7. Frank Finch, Los Alamos Scientific Laboratory, private communication April 1979.

8. "Environmental Survey of the Uranium Fuel Cycle," United States Atomic Energy Commission report WASH-1248 (Apr il 1974).

9. F. J. Walford, P. S. Atherton, and K. M. Hill, "Energy Costs of Inputs to Nuclear Power," Energy Policy 4 , 166 (1976). 
10. Alton J. Frabetti, "A Study to Develop Energy Estimates of Merit for Selected Fuel Technologies," Development Science, Inc., report DSI-038 (September 1975).

11. C. T. Rombough and B. V. Koen, "Total Energy Investments In Nuclear Power Plants," Nuclear Technology 26, 5 (1975).

12. R. Salmon, "A Procedure and a Computer Code (POWERCO) for Calculating the Cost of Electricity Produced by Nuclear Power Stations," Oak Ridge Nationa 1 Laboratory report ORNL-3944 (June 1966).

13. R. W. Hardie, "LPC, A Code for Calculating Levelized Power Costs for Electrical Generating Plants," to be published.

14. R. W. Hardie and J. H. Chamberlin, "Analys is of Electrical Power Generation Costs," Nuclear Technology 33, 212-222 (Apri1 1977).

i5. A. Wohlstetter, T. A. Brown, G. Jones, D. McGarvey, H. Rowen, V. Taylor, and R. Wohlstetter, "Moving Toward Life In a Nuclear Armed Crowd?" Arms Control and Dis armament Agency report ACDA/PAB-263 (Apri1 1976).

16. H. A. Dayem, D. D. Cobb, R. J. Dietz, E. A. Hakkila, J. P. Shipley, and D. B. Smith, "Dynamic Materials Accounting In the Back End of the Light Water Reactor Fuel Cycle," Nuclear Technology 43, 222 (1979).

17. "Environmental Data for Energy Technology Policy Analysis," United States Department of Energy report HCP/EV-6119/1 (January 1979).

18. "Proposed Final Environmental Statement, Liquid Metal Fast Breeder Reactor Program," United States Atomic Energy Commission report WASH-1535 (December 1974).

19. "Environmental Deve lopment Plan: Uranium Mining, Milling and Conversion," United States Department of Energy report DOE/EDP-0058 (August 1979).

20. E. M. Wewerka, J. M. Willi ams, N. E. Vanderborgh, A. W. Harmon, P. Wagner, P. L. Wanek, and J. D. 01 son, "Trace Element Characterization of Coal Wastes - Second Annual Progress Report," Los Alamos Scientific Laboratory report LA-7360-PR (July 1978)

21. L. Sagan, "Radiation and Human Health," EPRI Journal (September 1979).

22. "General Environmental Statement on the Use of Recycle Plutonium in Mixed Oxide Fue 1 in LWRs," United States Atomic Energy Commission report WASH1327 (August 1974).

23. "The Tennessee Valley Region Study: Potential Year 2000 Radiological Dose to Population Resulting From Nuclear Facility Operations," United States Department of Energy report DOE/ET-0064/2 (June 1978).

24. "Report to the American Physical Society on the Study Group on Nuclear Fue 7 Cycles and Waste Management," Reviews of Modern Physics 50, S1 (January 1978). 
25. "Reacior Safety Study: An Assessment of Accident Risks in U.S. Commerciai Nuclear Power Plants," United States Nuclear Regulatory Commission report WASH-1400 (NUREG-75/014) (October 1975).

26. "CRBRP Risk Assessment Report," Clinch River Breeder Reactor Project report CRBRP-1 (March 1977).

27. Robert D. Burns III, Los Alamos Scientific Laboratory, private communication, October 1979 .

28. John Graham, "Commercial Viability: A Complex Issue," Nuclear News $\underline{55}$ (February 1978).

29. "Code of Federal Regulations, Energy: 10CFR50.40," Office of the Federal Register (January 1977).

30. T. L. Montgomery and D. J. Rose, "Some Institutional Problems of the U.S. Nuclear Industry," Technology Review 53, (March/April 1979). 


\section{APPENDIX}

\section{DATA BASE}

The data used for this study can be grouped into two general categories-reactor-dependent data and reactor-independent data. Table A-I gives a brief description of each reactor type, and Table A-II presents reactor-dependent data that are associated with the reactor itself. Table A-III presents reactor-dependent data that are associated with support facilities such as fabrication and reprocessing plants. Reactor capital costs and operation and maintenance costs are also included in Table A-III to assist t'. a reader in comparing these costs.

Reactor-independent data are presented in Table A-IV. Included in this type of data are money costs, enrichment costs, thorium costs, fabrication and reprocessing times, and process loss fractions.

The NASAP study was the source for most of the data used in this evaluation. A notable exception was the FBR reactor design information, which was taken from D. R. Haffner and R. W. Hardie, "Reactor Physics Parameters of Alternative Fueled Fast Breeder Reactor Core Designs," Nuclear Technology 42, 123-132 (February 1979). The LWR reactor design data were obtained from Combustion Engineering through the Hanford Engineering Development Laboratory. An informal Oak Ridge National Laboratory report, "Draft NASAP Provisiona? Data Base," was the basis for the economic data. This data base is very similar, if not identical, to the data base in the final draft of the NASAP report.

Finally Table A-V presents energy requirements of various fuel cycle facilities. These requirements are given on an annual basis and include both embodied and operation energy usage. 
TABLE A-I

DESCRIPTION OF REACTORS

Reactor Name

LWR-U5 (LE)+U
LWR-PU+U
LWR-PU+Th
LWR-U3- (DE)+U+Th

$F B R-P U+U / U / U$

FBR-Pu+U/U/Th

\section{Description}

Pressurized light-water reactor, Combustion Engineering design, low-enriched ( $\approx 3 \%)$ $235 \mathrm{U}$ fissile fuel, $238 \mathrm{U}$ fertile fuel, standard burn up.

Pressurized light-water reactor, Combustion Engineering design, $\mathrm{Pu}$ fissile fuel, $238 \mathrm{U}$ fertile fuel, standard burn-up.

Pressurized light-water reactor, Combustion Engineering design, $P u$ fissile fuel, Th fertile fuel, standard burn-up.

Pressurized light-water reactor, Combustion Engineering design, denatured $233 \mathrm{U}$ fissile fue 1 ( $\leq 12 \% \quad 233 \mathrm{U}$ in $U), 238 \mathrm{U}$ and Th fertile fuel, standard burn-up.

Fast breeder reactor, low-temperature oxide design, $\mathrm{Pu}$ fissile fuel, $238 \mathrm{y}$ fertile fuel, $B R=1.355$.

Fast breeder reactor, low-temperature oxide design, Pu fissile fuel, 238y fertile fuel in core and axial blanket, Th fertile fuel in radial blanket, $B R=1.349$. 
Name LWR-U5 (LE)+U

Electrical Power Level (MWe) 1270

Recirculating Power (MWe) 30 (est)

Thermal Power Level (MWt) 3800

Capacity Factor

$(\%)$ 70

Capital Cost $(\$)^{a}$ $690 \times 1.27 \times 10^{6}$

Capital Replacement Rate (\%/yr) 0.35

Decommissioning Cost

(\$) $0.05 \times 690 \times 1.27 \times 10^{6}$

Salvage Value (\$) 0

Plant Lifetime (yr) 30

Fixed 0\&M Charges $(\$ / y r)$ $16.5 \times 10^{6}$

Variable 0\&M Charges ( $\$ / y r)$ $1.3 \times 10^{6}$

Fuel Residence Time $(y r) \ldots \ldots \ldots \ldots \ldots \ldots$

Average Fuel Discharge Exposure (MWt $\cdot$ day/kq Hil) ... 30.4

Conversion or Breeding Ratio 0.59

Description of Plant: Pressurized light-water reactor, Combustion Engineering design, low-enriched $(\approx 3 \%){ }^{235} U$ fuel, standard burn-up.

Includes owner's cost during construction and interest during construction; is based on a 1.3 GWe reactor size. 


\section{TABLE A-II (cont) \\ FUEL MANAGEMENT DATA [LWR-UR(LE)+U]}

\begin{tabular}{|c|c|c|c|c|}
\hline Material & $\begin{array}{r}\text { Initial Core } \\
(\mathrm{kg})\end{array}$ & $\begin{array}{l}\text { Eq. Charge } \\
(\mathrm{kg} / \mathrm{yr})\end{array}$ & $\begin{array}{c}\text { Eq. Discharge } \\
(\mathrm{kg} / \mathrm{yr})\end{array}$ & $\begin{array}{c}\text { Final Discharge } \\
(\mathrm{kg})\end{array}$ \\
\hline${ }^{232} \mathrm{Th}$ & 0 & 0 & 0 & 0 \\
\hline $233 \mathrm{u}$ & 0 & 0 & 0 & 0 \\
\hline $235 U$ & 2201 & 972 & 236 & 1363 \\
\hline${ }^{238} \mathrm{U}$ & 97111 & 31270 & 30270 & $\begin{array}{ll}98 & 1.38\end{array}$ \\
\hline Fiss Pu & 0 & 0 & 213 & 544 \\
\hline${ }^{240} \mathrm{Pu}$ & 0 & 0 & 74 (est) & 189 (est) \\
\hline Total HM & 99312 & $32 \quad 242$ & 31198 & 100499 \\
\hline
\end{tabular}


TABLE A-II (cont)

REACTOR DATA

Name

LWR-Pu+U

Electrical Power Level (MWe)

1270

Recirculating Power (MWe).

30 (est)

Thermal Power Level (MWt)

3800

Capacity Factor $(\%)$

70

Capital Cost $(\$)^{a}$

$690 \times 1.27 \times 10^{6}$

Capital Replacement

Rate

$(\% / y r)$

0.35

Decommissioning Cost

(\$) $0.05 \times 690 \times 1.27 \times 10^{6}$

Salvage Value $(\$)$ 0

Plant Lifetime (yr) 30

Fixed O\&M Charges $(\$ / y r)$ $16.5 \times 10^{6}$

Variable O\&M Charges $(\$ / y r)$ $1.3 \times 10^{6}$

Fuel Residence Time (yr) 3

Average Fuel Discharge Exposure (1 (1Wt . day $/ \mathrm{kg} \mathrm{HM}) \ldots . .30$ Conversion or Breeding Ratio

Description of Plant: Pressurized light-water reactor, Combustion Engineering design, $\mathrm{Pu}$ and ${ }^{238} \mathrm{U}$ fuel, standard burn-up.

Includes owner's cost during construction and interest during construction; is based on a 1.3 GWe reactor size. 
TABLE A-II (cont)

FUEL MANAGEMENT DATA (LWR-Pu $+U)$

\begin{tabular}{|c|c|c|c|c|}
\hline Material & $\begin{array}{c}\text { Initi a) Core } \\
(\mathrm{kg})\end{array}$ & $\begin{array}{l}\text { Eq. Charge } \\
(\mathrm{kg} / \mathrm{yr})\end{array}$ & $\begin{array}{c}\text { Eq. Discharge } \\
(\mathrm{kg} / \mathrm{yr})\end{array}$ & $\begin{array}{c}\text { Final Discharge } \\
(\mathrm{kg})\end{array}$ \\
\hline${ }^{232} \mathrm{Th}$ & 0 & 0 & 0 & 0 \\
\hline${ }^{23} 3_{U}$ & 0 & 0 & 0 & 0 \\
\hline $235_{U}$ & 710 & 211 & 130 & 503 \\
\hline $238 U$ & 99196 & 29473 & 28864 & 92473 \\
\hline Fiss Pu & 2040 & 1349 & 987 & 3813 \\
\hline${ }^{240} \mathrm{Pu}$ & 708 (est) & 468 (est) & 494 (est) & 1906 (est) \\
\hline Total HM & 102789 & 31979 & 30842 & 100146 \\
\hline
\end{tabular}


TABLE A-II (cont)

REACTOR DATA

Name

LWR-Pu+Th

Electrical Power Level (MWe)

1270

Recirculating Power (MWe) 30 (est)

Thermal Power Level (MWt) 3800

Capacity Factor

$(\%)$ 70

Capital Cost $(\$)^{\mathrm{a}}$ $690 \times 1.27 \times 10^{6}$

Capital Replacement Rate (\%/yr) 0.35

Decommissioning Cost (\$) $0.05 \times 690 \times 1.27 \times 10^{6}$

Salvage Value $(\$)$

Plant Lifetime (yr)

Fixed 0\&M Charges

$(\$ / y r)$ 30

Variable 08M Charges ( $\$ / y r$ ) $16.5 \times 10^{6}$

Fuel Residence Time (yr) $1.3 \times 10^{6}$

Average Fue? Discharge Exposure (MWt - day/kg HM) ... 34 (est)

Conversion or Breeding Ratio

Description of Plant: Pressurized light-water reactor, Combustion Engineering design, Pu and Th fuel, standard burn-up.

ancludes owner's cost during construction and interest during construction; is based on a 1.3 GWe reactor size. 
TABLE A-II (cont)

FUEL MANAGEMENT DATA (LWR-PU + U)

\begin{tabular}{|c|c|c|c|c|}
\hline Material & $\begin{array}{r}\text { Initial Core } \\
(\mathrm{kg})\end{array}$ & $\begin{array}{l}\text { Eq. Charge } \\
(\mathrm{kg} / \mathrm{yr})\end{array}$ & $\begin{array}{l}\text { Eq. Discharge } \\
(\mathrm{kg} / \mathrm{yr})\end{array}$ & $\begin{array}{c}\text { Final Discharge } \\
(\mathrm{kg})\end{array}$ \\
\hline${ }^{232} \mathrm{Th}$ & 89091 & 25851 & 25385 & 80683 \\
\hline $233 \mathrm{U}$ & 0 & 0 & 324 & 734 \\
\hline${ }^{235} \mathrm{U}$ & 0 & 0 & 4 & 5 \\
\hline${ }^{238} \mathrm{U}$ & 0 & 0 & 0 & 0 \\
\hline Fiss $\mathrm{Pu}$ & 3129 & 1780 & 942 & 4249 \\
\hline${ }^{240} \mathrm{Pu}$ & 1085 (est) & 618 (est) & 417 (est) & 2124 (est) \\
\hline Total HM & 93519 & 29101 & 27935 & 91051 \\
\hline
\end{tabular}




\section{TABLE A-II (cont)}

REACTOR DATA

Name $L W R-U 3(D E)+U+T h$

Electrical Power Level (MWe) .1270

Recirculating Power (MWe). 30 (est)

Thermal Power Level (MWt) 3800

Capacity Factor

(\%) .70

Capital Cost $(\$)^{2}$ $690 \times 1.27 \times 10^{6}$

Capital Replacement Rate $(\% / y r) \ldots \ldots \ldots \ldots \ldots . . \ldots \ldots$

Decommissioning Cost $(\$) \ldots \ldots \ldots \ldots \ldots \ldots \ldots \ldots .0 .05 \times 690 \times 1.27 \times 10^{6}$

Salvage Value $(\$) \ldots \ldots \ldots \ldots \ldots \ldots \ldots \ldots \ldots \ldots \ldots \ldots \ldots \ldots \ldots \ldots \ldots$

Plant Lifetime $(y r) \ldots \ldots \ldots \ldots \ldots \ldots \ldots \ldots \ldots \ldots \ldots \ldots \ldots \ldots \ldots \ldots$

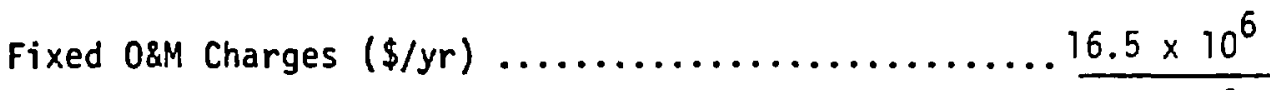

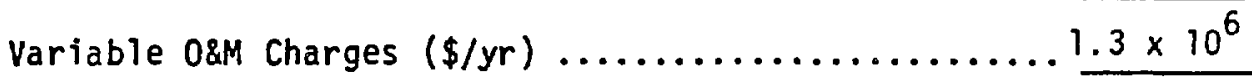

Fuel Residence Time $(y r) \ldots \ldots \ldots \ldots \ldots \ldots \ldots . \ldots . \ldots . \ldots$

Average Fuel Discharge Exposure (MWt - day/kg HMi) ....34 (est) Conversion or Breeding Ratio

Description of Plant: Pressurized light-water reactor, Combustion Engineering design, denatured $233 U$ fuel $(\leqslant 12 \% 233 U$ in $U)$ plus Th.

ancludes owner's cost during construction and interest during construction; is based on a 1.3 GWe reactor size. 
TABLE A-II (cont)

FUEL MANAGEMENT DATA [LWR-U3(DE)+U+Th]

\begin{tabular}{|c|c|c|c|c|}
\hline Material & $\begin{array}{r}\text { Initial Core } \\
(\mathrm{kg})\end{array}$ & $\begin{array}{l}\text { Eq. Charge } \\
(\mathrm{kg} / \mathrm{yr})\end{array}$ & $\begin{array}{c}\text { Eq. } \begin{array}{l}\text { Discharge } \\
(\mathrm{kg} / \mathrm{yr})\end{array} \\
\end{array}$ & $\begin{array}{c}\text { Final Discharge } \\
(\mathrm{kg})\end{array}$ \\
\hline${ }^{232} \mathrm{Th}$ & 73602 & 21097 & 20681 & 65007 \\
\hline${ }^{233} U$ & 2394 & 913 & 541 & 2064 \\
\hline $235_{U}$ & 36 & 47 & 52 & 220 \\
\hline${ }^{238} U$ & 17527 & 6835 & 6516 & 22794 \\
\hline Fiss $\mathrm{Pu}$ & 0 & 0 & 77 & 220 \\
\hline${ }^{240} \mathrm{Pu}$ & 0 & 0 & 27 (est) & 76 (est) \\
\hline Total HM & 93558 & 29107 & 28113 & 91329 \\
\hline
\end{tabular}


TABLE A-II (cont)

REACTOR DATA

Name

FBR-Pu+U/U/U

Electrical Power Level (MWe) 1196

Recirculating Power (MWe).

Thermal Power Level (MWt) 3736

Capacity Factor $(\%) \ldots \ldots \ldots \ldots \ldots \ldots \ldots \ldots \ldots \ldots \ldots$

Capital cost $(\$)^{a}$. $960 \times 1.196 \times 10^{6}$

Capital Replacement Rate $(\% / y r) \ldots \ldots \ldots \ldots \ldots \ldots . . . \ldots \ldots$

Decommissioning Cost $(\$)$ $0.05 \times 960 \times 1.196 \times 10^{6}$

Salvage Value ( $\$$ ) 0

Plant Lifetime (yr) 30

Fixed O\&M Charges ( $\$ / y r$ ) $20.3 \times 10^{6}$

Variable O\&M Charges ( $\$ / y r$ ) $1.2 \times 10^{6}$

Fuel Residence Time (yr) 2 (core); 5 (rad blkt)

Average Fuel Discharge Exposure (MWt . day/kg HM).... 62 (core)

Conversion or Breeding Ratio $C R=1.040 ; B R=1.355$

Description of Plant: Fast breeder reactor, low-temperature oxide design, Pu and ${ }^{238} U$ core, ${ }^{238} U$ axial and radial blankets.

ancludes owner's cost during construction and interest during construction; is based on a 1.3 GWe reactor size. 


\section{TABLE A-II (cont) \\ CORE}

FUEL MANAGEMENT DATA (FBR-PU+U/U/U)

\begin{tabular}{|c|c|c|c|c|c|}
\hline Material & $\begin{array}{c}\text { Initia) Core } \\
(\mathrm{kg})\end{array}$ & $\begin{array}{c}\mathrm{Eq.} \mathrm{Charge} \\
(\mathrm{kg} / \mathrm{yr})\end{array}$ & $\begin{array}{l}\text { Eq. Discharge } \\
(\mathrm{kg} / \mathrm{yr})\end{array}$ & Fina? & $\begin{array}{l}\text { Discharge } \\
(\mathrm{kg})\end{array}$ \\
\hline${ }^{232}$ Th & 0 & 0 & 0 & & 0 \\
\hline $233_{U}$ & 0 & 0 & 0 & & 0 \\
\hline $235 u$ & 94 & 38 & 20 & & 66 \\
\hline $238 u$ & $31 \quad 176$ & 12644 & 11528 & 29 & 356 \\
\hline Fiss $\mathrm{Pu}$ & 3689 & 1496 & 1551 & 3 & 778 \\
\hline${ }^{240} \mathrm{Pu}$ & 1334 & 541 & 599 & & 458 (est) \\
\hline Total HM & $36 \quad 458$ & 14786 & 14786 & 36 & 458 \\
\hline
\end{tabular}


TABLE A-II (cont)

A.XIAL BLANKET

FUEL MANAGEMENT DATA (FBR-PU+U/U/U)

\begin{tabular}{|c|c|c|c|c|c|}
\hline Material & $\begin{array}{l}\text { Initial Core } \\
(\mathrm{kg})\end{array}$ & $\begin{array}{l}\text { Eq. Charge } \\
(\mathrm{kg} / \mathrm{yr})\end{array}$ & $\begin{array}{l}\text { Eq. Discharge } \\
(\mathrm{kg} / \mathrm{yr}) \\
\end{array}$ & Fina & $\begin{array}{l}7 \text { Discharge } \\
(\mathrm{kg})\end{array}$ \\
\hline${ }^{232} \mathrm{Th}$ & 0 & 0 & 0 & & 0 \\
\hline $233 U$ & 0 & 0 & 0 & & 0 \\
\hline $235 u$ & 62 & 25 & 19 &. & 52 \\
\hline $238 U$ & 20490 & 8310 & 8139 & 20 & 186 \\
\hline Fiss $\mathrm{Pu}$ & 0 & 0 & 154 & & 251 \\
\hline${ }^{240} \mathrm{Pu}$ & 0 & 0 & 4 & & 7 (est) \\
\hline Total HM & 20551 & 8335 & 8335 & 20 & 551 \\
\hline
\end{tabular}


TABLE A-II (cont)

RADIAL BLANKET

FUEL MANAGEMENT DATA (FBR-PU+U/U/U)

\begin{tabular}{|c|c|c|c|c|}
\hline Material & $\begin{array}{c}\text { Initial Core } \\
(\mathrm{kg})\end{array}$ & $\begin{array}{l}\text { Eq. Charge } \\
(\mathrm{kg} / \mathrm{yr})\end{array}$ & $\begin{array}{c}\text { Eq. Oischarge } \\
(\mathrm{kg} / \mathrm{yr})\end{array}$ & $\begin{array}{c}\text { Final } \begin{array}{l}\text { Discharge } \\
(\mathrm{kg})\end{array} \\
\end{array}$ \\
\hline${ }^{232} \mathrm{Th}$ & 0 & 0 & 0 & 0 \\
\hline${ }^{233} U$ & 0 & 0 & 0 & 0 \\
\hline${ }^{235} U$ & 111 & 18 & 16 & 101 \\
\hline $238 u$ & 36095 & 5987 & 5808 & 36033 \\
\hline Fiss $\mathrm{Pu}$ & 0 & 0 & 159 & 555 \\
\hline${ }^{240} \mathrm{Pu}$ & 0 & 0 & 9 & 31 \\
\hline Total HM & 37016 & 6004 & 6004 & 37016 \\
\hline
\end{tabular}


TABLE A-II (cont)

REACTOR DATA

Name

FBR-Pu+U/U/Th

Electrical Power Level (MWe) ................. 1196

Recirculating Power (MWe).

Thermal Power Level (MWt)

3736

Capacity Factor

$(\%)$

70

Capital cost

(\$) $a$ $960 \times 1.196 \times 10^{6}$

Capital Replacement Rate ( $\% / y r)$ 0.35

Decommissioning Cost

(\$) $0.05 \times 960 \times 1.196 \times 10^{6}$

Salvage Value

$(\$)$ 0

Plant Lifetime 30

Fixed O\&M Charges $(\$ / y r)$ $20.3 \times 10^{6}$

Variable 0\&M Charges ( $\$ / y r)$ $1.2 \times 10^{6}$

Fuel Residence Time (yr) 2 (core); 5 (rad blkt)

Average Fuel Discharge Exposure (MWt $\cdot$ day/kg $\left.H_{M}\right) \ldots .62$ (core)

Conversion or Breeding Ratio $C R=1.041 ; B R=1.349$

Description of Plant: Fast breeder reactor, low-temperature oxide design, Pu and ${ }^{238} U$ core, ${ }^{238} U$ axial blanket, ${ }^{232}$ Th radial blanket.

ancludes owner's cost during . nstruction and interest during construction; is based on a 1.3 GWe reactor size. 
TABLE A-II (cont)

CORE

FUEL MANAGEMENT DATA (FBR-PU+U/U/Th)

\begin{tabular}{|c|c|c|c|c|c|}
\hline Material & $\begin{array}{r}\text { Initia] Core } \\
(\mathrm{kg})\end{array}$ & $\begin{array}{l}\text { Eq. Charge } \\
(\mathrm{kg} / \mathrm{yr}) \\
\end{array}$ & $\begin{array}{c}\text { Eq. Discharge } \\
(\mathrm{kg} / \mathrm{yr})\end{array}$ & Fina 1 & $\begin{array}{l}\text { Discharge } \\
(\mathrm{kg})\end{array}$ \\
\hline${ }^{232} \mathrm{Th}$ & 0 & 0 & 0 & & 0 \\
\hline${ }^{233} \mathrm{U}$ & 0 & 0 & 0 & & 0 \\
\hline $235 u$ & 94 & 38 & 20 & & 56 \\
\hline${ }^{238} \mathrm{U}$ & 31172 & 12642 & 11517 & 29 & 337 \\
\hline Fiss Pu & 3694 & 1498 & 1554 & 3 & 785 \\
\hline${ }^{240} P_{u}$ & 1336 & 542 & 600 & 1 & 461 \\
\hline Total HM & 36461 & 14788 & 14788 & 36 & 461 \\
\hline
\end{tabular}




\section{TABLE A-II (cont)}

AXIAL BLANKET

FUEL MANAGEMENT DATA (FBR-Pu+U/U/Th)

Material

${ }^{232}$ Th

$233 \mathrm{U}$

$235 \mathrm{U}$

${ }^{238} \mathrm{U}$

Fiss $\mathrm{Pu}$

${ }^{240} \mathrm{Pu}$

Total HM
Initial Core

$(\mathrm{kg})$

0

0

62

20453

0

0

20515
Eq. Charge

$(\mathrm{kg} / \mathrm{yr})$

0

0

25

8295

0

0

8320
Eq. Discharge $(\mathrm{kg} / \mathrm{yr})$

0

0

19

8119

159

4

8320
Final Discharge (kg)

0

0

52

20139

261

7

$205 i 5$ 
TABLE A-II (concluded)

RADIAL BLANKET

FUEL MANAGEMENT DATA (FBR-Pu+U/U/Th)

\begin{tabular}{|c|c|c|c|c|}
\hline Material & $\begin{array}{r}\text { Initia) Core } \\
(\mathrm{kg})\end{array}$ & $\begin{array}{l}\text { Eq. Charge } \\
(\mathrm{kg} / \mathrm{yr})\end{array}$ & $\begin{array}{l}\text { Eq. Discharge } \\
(\mathrm{kg} / \mathrm{yr})\end{array}$ & $\begin{array}{c}\text { Final Discharge } \\
(\mathrm{kg})\end{array}$ \\
\hline${ }^{232} \mathrm{Th}$ & $33 \quad 119$ & 5373 & 5212 & 32394 \\
\hline${ }^{233} \mathrm{U}$ & 0 & 0 & 146 & 507 \\
\hline${ }^{235} U$ & 0 & 0 & 0 & 0 \\
\hline${ }^{238} U$ & 0 & 0 & 0 & 0 \\
\hline Fiss Pu & 0 & 0 & 0 & 0 \\
\hline${ }^{240} \mathrm{Pu}$ & 0 & 0 & 0 & 0 \\
\hline Total $\mathrm{HM}$ & 33119 & 5373 & 5373 & $33 \quad 119$ \\
\hline
\end{tabular}


REACTOR-DEPENDENT COST DATA

\begin{tabular}{|c|c|c|c|c|c|}
\hline $\begin{array}{c}L W R \\
U 5 \text { (LE)+U } \\
\underline{U}\end{array}$ & $\begin{array}{r}\text { LWR } \\
\text { Pu+U }\end{array}$ & $\begin{array}{l}\text { LWR } \\
\text { Pu+Th }\end{array}$ & $\begin{array}{c}\text { LWR } \\
U 3(D E)+U+T h\end{array}$ & $\begin{array}{c}F B R \\
P u+U / U / B\end{array}$ & $\begin{array}{c}\text { FBR } \\
P u+U / U / T h\end{array}$ \\
\hline $\begin{array}{r}1270 \\
690\end{array}$ & $\begin{array}{r}1270 \\
690\end{array}$ & $\begin{array}{r}1270 \\
690\end{array}$ & $\begin{array}{r}1270 \\
690\end{array}$ & $\begin{array}{r}1196 \\
960\end{array}$ & 960 \\
\hline
\end{tabular}

Power Leve 1 (MWe)

690

690

690

960

Operation and Maintenance Charges ( $\$ / y r)$

Fixed

Variable

Fabrication Cost ( $\$ / \mathrm{kg} \mathrm{HM})$

Core

Axial Blanket

Radial B1anket

$\begin{array}{cc}110 & 370 \\ - & -\end{array}$

380

570

580

580

$$
\text { Cost ( } \$ / \mathrm{kg} \mathrm{HM})
$$$$
\text { Core }
$$$$
\text { Axial Blanket }
$$$$
\text { Radial Blanket }
$$

$\begin{array}{cc}370 & 370 \\ - & - \\ - & -\end{array}$

410

$-$

580

580

Reprocessing Cost ( $\$ / \mathrm{kg} \mathrm{HM}$ )

Radial Blanket

Spent Fuel Shipping Cost ( $\$ / \mathrm{kg} \mathrm{HM}$ )

\section{5}

10

Waste Shipping Cost ( $\$ / \mathrm{kg} \mathrm{HM)}$

Waste Storage Cost ( $\$ / \mathrm{kg} \mathrm{HM})$

Permanent Spent Fuel Storage $(\$ / \mathrm{kg} \mathrm{HM})$

50

Total Back-End Fuel Handling Cost ( $\$ / \mathrm{kg} \mathrm{HM}$ ) Core
Axial Bl anket
Radial Blanket

50 
Money Costs

Debt Interest (\%)

2.5

Equity Return (\%)

7.0

Debt Fraction

0.55

Equity Fraction

0.45

Effective Return (\%)

4.5

Income Tax Rate (\%)

50.0

Property Tax Rate (\%)

2.5

Property Insurance Rate (\%)

0.25

Interim Capital Replacement Rate (\%)

0.35

Irvestment Tax Credit Rate (\%)

0.0

Enrichment Tails Composition (\%)

0.2

Enrichment Cost ( $\$ / \mathrm{kg}$ SWU)

100.0

$\mathrm{U}_{3} \mathrm{O}_{8}$ to $\mathrm{UF}_{6}$ Conversion Cost $(\$ / \mathrm{kg} \mathrm{U})$

4.0

Thorium Cost $\left(\$ / 7 \mathrm{~b} \quad \mathrm{ThO}_{2}\right)$

15.0

$U_{3} 0_{8}$ to $U_{6}$ Losses $(\%)$

0.5

Fabrication Losses (\%)

1.0

Reprocessing Losses (\%)

1.0

Fabrication Lead Time ( $y r$ )

1.0

Reprocessing Lag Time ( $y r$ )

1.0 
TABLE A-V

ANNUAL ENERGY REQUIREMENTS OF FUEL CYCLE FACILITIES

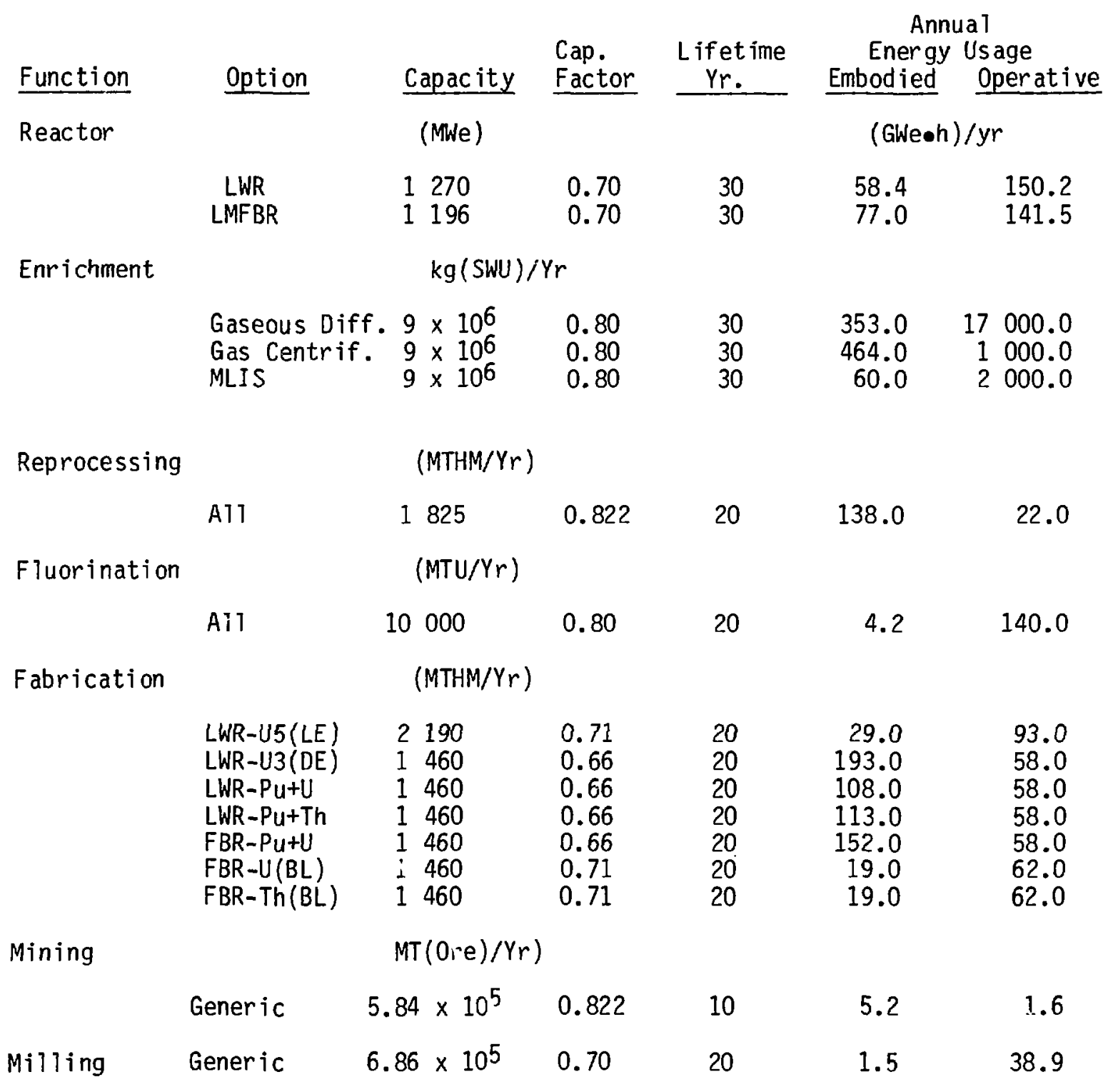

